Article

\title{
New Express Delivery Service and Its Impact on $\mathrm{CO}_{2}$ Emissions
}

\author{
Dragan Lazarević $^{1, *(\mathbb{D})}$, Libor Švadlenka ${ }^{2}$, Valentina Radojičić ${ }^{1}$ and Momčilo Dobrodolac $^{1}$ (D) \\ 1 Faculty of Transport and Traffic Engineering, University of Belgrade, 11000 Belgrade, Serbia; \\ valentin@sf.bg.ac.rs (V.R.); m.dobrodolac@sf.bg.ac.rs (M.D.) \\ 2 Jan Perner Transport Faculty, University of Pardubice, 53210 Pardubice, Czech Republic; \\ libor.svadlenka@upce.cz \\ * Correspondence: d.lazarevic@sf.bg.ac.rs; Tel.: +381-11-3091-245
}

Received: 2 December 2019; Accepted: 6 January 2020; Published: 7 January 2020

check for updates

\begin{abstract}
A rapid development of Internet technologies creates new opportunities for e-commerce, which is one of the fastest-growing segments of the entire economy. For policymakers, the most important aspects of e-commerce are related to the cost reduction in transportation, facilitation of administration and communication, innovations at the market level, and environmental issues. An unavoidable part of the e-commerce production process is related to the postal service. New market expectations of modern society lead to the consideration of upgrading the traditional express delivery service in terms of time availability. In this paper, we propose a new 24-h availability of postal and courier service so-called "post express nonstop". To assess the potential demand for this kind of service, we propose a forecasting procedure based on the Bass diffusion model. In particular, the research is directed toward the examination of environmental issues, considering both types of services-traditional and the proposed new one. A comparison is done by analyzing $\mathrm{CO}_{2}$ emissions in the last-mile delivery of goods to the users' addresses. The experiment was carried out in the city of Belgrade, simulating the last-mile delivery under realistic conditions and controlling the fuel consumption and $\mathrm{CO}_{2}$ emissions. In accordance with the results of this experiment and the forecasted number of postal items, a projection of $\mathrm{CO}_{2}$ emissions for the new service from 2020 to 2025 was carried out. The results show a significant contribution of the proposed new express delivery service to environmental well-being and sustainability.
\end{abstract}

Keywords: postal items forecasting; express delivery service; social change; time availability; fuel consumption; $\mathrm{CO}_{2}$ emissions

\section{Introduction}

New digital solutions, such as e-commerce, are creating new opportunities for companies of all sizes by increasing market access for customers, supply chains, and competitors, and by reducing trade costs. The organizations tend to provide products or services of the highest quality, to retain the existing customers and generate new ones, with the final aim to increase their profits. At the same time, the service sector in developed countries employs about $70 \%$ of the total number of employees, with a growing tendency. Based on these facts, a conclusion may be reached that the service sector activities represent a significant segment of a state's development. The production itself, without products' placement, export, transport, etc., has no major contribution. Companies, first of all, postal and courier, dealing with the distribution of items are of great importance in this area. In that way, express delivery companies have a huge impact on the business and private life of each individual and therefore on the functioning of the entire society. 
Social change and the rapid development of Internet technologies in many ways influence the changing behavior, habits, needs, and responsibilities of each individual [1,2]. Modern business requires an increased commitment to work and thus forms a model by which a person spends most of the day in the realization of business activities. Moreover, modern business significantly affects other life activities and obligations during the working days. For example, a problem may arise when there is a need to perform certain private duties during working hours, such as the fulfillment of certain administrative duties in the state administration, shopping in facilities whose working hours coincide with the working hours of an individual, etc. On the other hand, on weekends, many companies and service providers still do not work. Some authors have analyzed how social changes and the problems they bring about have been addressed by different national governments [3].

The subject of this research is the impact of the described social change on the sustainability of the postal service. Namely, almost all postal companies in the territory of the Republic of Serbia have working hours like most other companies and institutions in the country. In this way, the population working in the aforementioned entities is generally unable to use the postal services. This paper considers the new market expectations which relate to the upgrading of traditional postal services, without any restriction on the time availability.

Time availability is the most important service-quality parameter. It is an amount of time available to the users. Considering that users' and potential users' habits and needs change along with social change, and in line with the presence of developed competition in the market, it is essential for companies to conduct activities for improving their service offers. These activities could be a modification of the existing services or the introduction of the new ones.

Express delivery service that is offered by the designated postal operator in Serbia is analyzed in this paper. A designated postal operator is a postal operator that provides a universal postal service on the whole territory of a country. The result shows that the designated postal operator has the greatest time availability, regarding this service, in comparison to private courier companies in the market. Nevertheless, we propose a new express delivery service, "post express nonstop", which would be performed in periods of time that are not currently covered by the service, thus maximizing the time availability. In this way, the service would also be available to people who have been prevented from using it for the reasons described above; however, this would bring benefits to business customers as well. Finally, it is expected that the new service will have an impact on environmental well-being and sustainability, by reducing the level of $\mathrm{CO}_{2}$ in the transportation activities.

This research was conducted based on the current state reports about the express delivery service of the designated postal operator, as well as on people's views, interests, and needs for the proposed "post express nonstop" service. With that aim, a relevant questionnaire was created. The collected data were statistically analyzed in IBM SPSS Statistics v. 21 software (Statistical Package for the Social Science).

Modeling diffusion of the growth pattern of the new service is one of the focuses of this paper. The first papers in the field of forecasting new services appeared at the beginning of the second half of the twentieth century [4-9]. Diffusion theory is widely applied in order to forecast the adoption of a new service. The complexity of diffusion models is driven by the need to enhance the forecasting capability of these models and to improve their usefulness as a decision-making tool for managers $[10,11]$. The Bass diffusion model is frequently applied in modeling and forecasting of diffusion processes in marketing research and other disciplines. It has a significant impact on business decisions because it provides an insight on market adoption and determines whether to move forward with the new service.

In order to perform an assessment of the proposed service acceptance level, a demand forecast was conducted. For that purpose, the Bass diffusion model was used. In this paper, a suitable modification of the imitation parameter is proposed based on views of respondents that were obtained through the conducted research.

The final aim of the new proposed concept is to contribute to environmental sustainability. Nowadays, the social responsibility of companies in the segment of raising awareness and realization of activities for environmental protection is significantly increased. The reason for this is the increasing 
negative effects on the health of the living world, due to negligent behavior and business. We can say that there is a slightly greater responsibility for those companies which rely heavily on transportation for the implementation of their business activities; postal companies are certainly no exception. Transport still relies heavily on the use of fossil fuels [12]. The use of fossil fuels, due to significant $\mathrm{CO}_{2}$ emissions and other air pollution, is a growing problem and is gaining public attention [13]. Transport is responsible for approximately $30 \%$ of total $\mathrm{CO}_{2}$ emissions at the European Union level, of which $72 \%$ comes from road transport (express delivery companies in domestic traffic and last-mile delivery rely mostly on road transport). Emerging trends have led the EU to aim at reducing emissions from transport by $60 \%$ by 2050, compared to 1990 levels [14]. One of the ways to achieve this is to develop and implement a model for defining an optimal energy consumption strategy, such as REDGEM70 (REgionally Disaggregated Global Energy Model with 70 regions) [15].

There are different approaches that can lead to the reduction of negative emissions. The increasing investment in the development of electric and hybrid vehicle technologies (primarily in the area of battery autonomy and charging technology) is a clear sign that they represent the future of an environmentally responsible transport system $[16,17]$. These vehicles are still lacking in the real system, with cost and technology development being some of the main reasons. The use of alternative fuels (biofuels, electricity, and fossil fuels, such as CNG, LNG, LPG, and GTL) is another effective approach, which has some limitations (primarily technical ones) in implementation and operation. There are numerous studies dealing with alternative fuels, such as the choice of the most efficient alternative fuel, production, policies, and environmental impact of biodiesel, as well as an analysis of the perspective and possibilities of using vegetable oils and their derivatives in diesel engines [18-21].

One of the most cost-effective concepts that can effectively reduce fuel consumption and emissions is the application of the Eco-driving principle [22-24]. Across Europe, having an Eco-driving certificate is one of the obligations of all professional drivers. Habits, behavior, and responsiveness define the driving style, which, together with traffic conditions, has a significant impact on fuel consumption [25]. The concept is based on observation and anticipation while striving to keep the speed constant at as high a gear as possible and at lower engine speed. In addition, one of the key goals is to avoid unnecessary stops (at traffic lights, in the car column, etc.). The reason is high fuel consumption when a vehicle starts moving from a standstill.

Based on the above, it can be concluded that decisions made in traffic at the daily level (both by drivers and those who regulate transport policy) have an impact on human health. The Health Impact Assessment (HIA) process can generate indicators that can be used for a variety of purposes, the most important being reducing the negative impact that threatens it [26]. The importance of developing and applying all of these and similar concepts lies in the fact the negative impact on the environment has different negative consequences to the health of the living world [27-30].

The rest of the paper is organized as follows. The next section presents problem statement and development and applied methodology, including modification of the imitation parameter of the basic Bass model. The third section describes the implementation of the proposed concept in the city of Belgrade. The results of detailed analysis and the postal items forecasting for the "post express nonstop" service are given in the fourth section. The fifth section includes an analysis of the impact of the new service on the environment, i.e., on the $\mathrm{CO}_{2}$ emissions. Finally, some conclusions are given.

\section{Problem Statement and Research Methodology}

A concept of research for the improvement of time availability of express delivery services is proposed and applied in the paper. It is defined by the following steps:

Step 1: analysis of the current time availability of express delivery services on the considered territory-all companies that provide express delivery services in the observed territory are included in the analysis.

Step 2: proposal of activities for improvement of time availability—design of new service.

Step 3: Detailed analysis of proposed activity/activities—detailed analysis of the proposed new service. 
In the first step, the services of all operators are analyzed for the territory where the research was conducted. Particular attention is placed on the time periods when the service is offered to customers. In line with the collected data, in the second step, the activities for improvement of time availability are proposed. They could be related, first of all, to the modification of existing services or the introduction of new services. In this case, it is related to a proposed new service, "post express nonstop", which would be performed in periods of time that are not currently covered by the existing service. In the third step, it is necessary to conduct adequate analysis, which should prove or deny the need and justification of the implementation of the defined activity/activities. Analysis of the proposed service, "post express nonstop", included a combined approach based on statistical analysis and forecasting. For forecasting purposes, a modification of the Bass diffusion model is proposed. The modification is reflected in the use of a correction factor for the imitation parameter. This factor is formed based on the results of a survey conducted with customers and should reveal the social-change influence on the acceptance of a new service. Further on, the results of the application of the proposed concept at Belgrade territory are shown.

\subsection{Forecasting Demand for New Services}

A forecast can be defined as a prediction of future needs, which is expressed in quantitative terms. There are many forecast methods, and most of them are based on the perception that the future is a reproduction of the past. Different approaches to forecast are defined as follows:

- Time-based methods-based on the trend of known statistical data;

- Causal methods-based on the perception that the relationship between variables and causative factors from the past is retained in the future;

- Comparative approach-based on the perception that less-developed countries accept experiences and follow the example of more-developed countries;

- Expert assessments-based on the approach that takes into account knowledge and experience of experts from the relevant fields.

The basic division of the forecast methods is on statistical (based on statistical data) and nonstatistical (based on principles, such as judging, simple extrapolation, etc.) [31]. Forecasting demand for new services is based on an assessment of the market reaction, based on which the decision is made whether to start providing a new service or not. Each of the defined forecasting methods has certain advantages; therefore, it is possible that the best results can be achieved by combining them. As a consequence, a modern approach (a combination of statistical and nonstatistical methods) has emerged, and it includes the following [31]:

- Market research methods-commonly applied in cases with no statistical indicators that would represent the demand. They most often involve surveying and interviewing users;

- Expert opinions-represent the foundation of the principles based on attitudes and ideas arising from experience and can contribute to the development of the service and its launch to the market;

- Comparative methods-based on the use of diverse indicators from the market, that is, from the countries where the service is already present;

- Diffusion models or substitution models-mathematical in nature, these models are used to represent the new service's lifecycle curve.

The speed of accepting a new service is a function of various factors, such as [6] the benefits of the service in relation to the existing one/s and its simplicity and compatibility with existing operations. A diffusion speed can depend on the time at which an innovative service is introduced [32,33]. The success and speed of acceptance of the service can be influenced by various marketing activities. The development of new technologies and, above all, the improvement of Internet access have led to the emergence of diverse channels for the dissemination of information on services and products. One of the traditional approaches, which includes the concept of word of mouth, in practice, also 
provides good results [34-37]. Lately, this approach has been adapted to the modern way of life, thus separating the appearance form-electronic word of mouth (eWOM). It implies direct communication and exchange of information about a product or service between users, via the Internet. This fact is confirmed by the considerable number of works that have appeared in the literature recently, and they deal with the mentioned topic [38-40].

\subsection{Modification of the Imitation Parameter of the Basic Bass Model}

The Bass model is based on the importance of interaction between users and potential users for accepting a new service. The model identifies two groups of users:

- Innovators-users who easily and quickly accept new services and technologies. They are not influenced by other users, and they can be influenced by marketing;

- Imitators-users whose decisions dependent on the users who have already accepted the service. Various ways of social communication can have a significant impact on them.

In line with the selected user groups, the parameters of innovation $(p)$ and imitation $(q)$, are defined, and they essentially represent the main characteristics of the diffusion process. Bass argued that the probability of buying a new service was a linear function of the number of previous sales. He linked linearity to the characteristics of innovation and imitation [9]. In addition, on a similar basis, an innovative and imitation model is identified $[4,41]$.

The cumulative number of users, $N(t)$, who accepted the service in the period from its occurrence to a specific time, $t$, can be represented as follows:

$$
N(t)=\int_{0}^{t} s(t) d t=m \int_{0}^{t} f(t) d t=m F(t),
$$

where $s(t)$ is the intensity of accepting a new service, that is, the number of new users, which can be expressed with the following equation:

$$
s(t)=p m+(q-p) N(t)-\frac{q}{m} N^{2}(t)
$$

Diffusion models are also applicable in cases of lack of appropriate data [42,43]. Significant contributions in this segment are the performed meta-analyses, on the basis of which the mean values of the corresponding parameters, primarily innovation and imitation [33,44]. Various modifications of the model can be found in the literature [45-47].

One of the significant modifications to the Bass model involves the impact of marketing activities on the probability of acceptance of a new service. This is made possible by the introduction of parameters that reflect the impact of publicity, word-of-mouth effect, and advertising on the diffusion rate [48]. Price as an influential factor in accepting a new service was considered by introducing a coefficient of price elasticity [49]. Below are five of the most significant modifications to the Bass model. The generalized Bass model combines the probability of service acceptance and the effects of marketing mix variables on the diffusion process [50]. The two-phase diffusion model involves the analysis of the diffusion process before the service appears on the market. In the first phase, the service is announced, and users are informed about it, while in the second phase, it becomes available on the market [51]. In 1997, the Norton-Bass model was developed that links diffusion and substitution [47], which is of great importance when two technological generations of services compete in the market. Most diffusion models focus on the diffusion process at the service level, and a smaller number at the brand level. One such model, to evaluate brand sales, is a modified Bass model for the competitive market [52]. In the absence of statistics for the national market, it is appropriate to use multinational diffusion models, which combine the Bass model with a learning effect based on the experience of service diffusion in other countries [53]. 
In order to upgrade the forecasting procedure by including the influence of potential users' interest in using the new service, it was necessary to modify the basic Bass model, which does not consider this impact. The proposed modification implies a correction of the imitation parameter by introducing a correction factor, $\Delta c$, the value of which is based on certain results of the survey conducted on attitudes, interests, and needs for the new service.

$$
\Delta c=1-c_{q}
$$

where $c_{q}$ is an indicator of the behavior of users or potential users. It represents the percentage of those who are not interested in or abandon the service after some activities. If there is no change of opinions, $\Delta c$ takes the value 1. It can be determined based on statistics or appropriate research. When $\Delta c$ is introduced into Equation (2), we obtain $s_{c}(t)$ corrected the number of new users at a time, $t$ :

$$
s_{c}(t)=p m+(q \Delta c-p) N_{(t)}-\frac{q \Delta c}{m} N_{(t)}^{2} .
$$

In this way, the influence of the customer's interest in the analyzed service is introduced, which is an important factor in the diffusion process. At the same time, according to the authors' knowledge, this kind of customer's interest involvement in the diffusion cannot be found in the literature, making a corresponding innovation in the field.

\section{Implementation of the Proposed Concept in the City of Belgrade}

\subsection{Analysis of Time Availability of Express Delivery Services in the City of Belgrade}

Express postal items' delivery at the territory of Belgrade is performed by a designated postal operator and numerous private courier companies in line with the defined time frames. Analyzing the work of a designated postal operator, these times are, in dependence on the service type, first of all in compliance with the working time of postal network units, that is, with the working time of couriers.

Designated postal operator offers express delivery services, via one of the following service types: "instant delivery" — deadline for delivery is three hours within the same city; "same-day delivery" — deadline for delivery on the same day by 7 p.m.; "next-day delivery until 12 p.m." - deadline for delivery on a subsequent day, by 12 p.m.; "next-day delivery until 7 p.m." —deadline for delivery is by 7 p.m., on a subsequent day.

The research was conducted on the territory of Belgrade, where a working time of postal network units, on working days, is mostly from 8 a.m. to 7 p.m., which will be also adopted as maximal time availability. Couriers could theoretically be on the terrain within this time interval. Observing weekend days, on Saturdays, there are many operative postal network units most frequently within the time interval from 8 a.m. to 2 p.m., with the notice that, during that period, the last-mile delivery is mostly performed. On Sundays, the courier service of the designated postal operator does not work.

Private courier companies which cover Belgrade city territory have a lower level of time availability compared to the designated postal operator.

Regarding working time, there are certain exceptions, both regarding the working and weekend days; however, as such, they are not of interest to be included in the analysis.

The final conclusion of the analysis indicates that, within the time period from 7 p.m. until 8 a.m. (from Monday to Saturday), express delivery service is not executed, as well as in the period from 2 p.m. on Saturday until 8 a.m. on Monday.

\subsection{Proposal of Activities for Improvement of Time Availability—Proposal of "Post Express Nonstop" Service}

Periods when express delivery services are not being performed could be interesting to service providers, since necessities and habits are changing in society on a daily basis. The service "post express nonstop" is proposed, which has the biggest benefit toward the users, in the area of time-availability 
improvement. The concept is such that a service is performed in the period from 7 p.m. until 8 a.m. on working days, as well as on weekends, from 2 p.m. (on Saturday) until 8 a.m. (on Monday), that is, in the periods not covered by the traditional express delivery service. Service providing would be in accordance with the existing daily services instant delivery and same-day delivery, that is, the postal items would be delivered within three hours after their receipt, or until 8 a.m. Moreover, the principle similar to the one within next-day delivery service would be supported, that is, for the reception to be executed within the service "post express nonstop", and delivery on the next day (or later on the same day in case reception is executed during the period from midnight on) through the system of existing standard express delivery services. Equally, the reception could be executed via existing services, and delivery via "post express nonstop" service. Based on that, the following service options could be mentioned:

- $\quad$ "Post express nonstop" for now (delivery within three hours, reception limited on time until 5 a.m.);

- $\quad$ "Post express nonstop" until the morning (delivery is not within three hours; however, it is until 8 a.m., with reception possible until 5 a.m.);

- "Post express nonstop" for the day (delivery until 12 p.m. or 7 p.m.);

- Today for "post-express nonstop" (reception of postal items during the day, with delivery until 8 a.m. the next morning).

Service order would be executed via a call center, which would be active $24 \mathrm{~h}$ a day, reception on the sender's address, and delivery on recipient's address (in case it is executed within "post express nonstop" service- until the morning). Special (additional) services could be offered, with a notice that they must be in line with the laws and regulations regarding postal service.

Three tariff scenarios are proposed:

- Scenario I-price in accordance with daily services;

- Scenario II-20\% higher price in relation to daily services;

- Scenario III-20\% lower price in relation to daily services.

A reason for the service price increase is the need for mobilization of resources (of manpower, vehicles, processing systems, etc.) in the period out of the standard working time. The introduction of a new service is a fundamental problem that managers of different companies in service activity face regularly. Appropriate marketing support strategies must be specified so that more users accept the service [54]. After accepting the service by the market, special benefits for big users could be introduced, as well as other variations in relation to the initial offer, and in line with elements of the marketing mix. "Post express nonstop" service has, besides the direct financial income through service payment to the operator, additional positive effects, both for the operator and for society as a whole. Transfer of express postal items within internal transport relies on road traffic. Belgrade territory, where service would be provided, is characterized by daily traffic rush hours and traffic jams. Avoiding these situations in traffic and decreasing commuting frequency during hours of the peak load of the traffic network would contribute to the reduction of traffic congestion and driving time. The mentioned results in additional benefits include higher efficiency of the workforce, shorter service time, reduction of transport means' amortization, increase of energetic efficiency in the system, the possibility of serving more addresses per courier in a certain time period, less contribution to traffic jam occurrence, reduction of harmful gas emissions, etc. This is the reason why Scenario III-a lower price-is considered in this paper. A similar pilot project was implemented in Sao Paulo, which involved freight deliveries to retailers overnight. Positive experiences have influenced many retailers to implement this concept in their own business [55].

The detailed analysis encompasses researching needs and justifications for "post express nonstop" service implementation, as well as prognosis-assessment of its acceptance by users in the future. It is presented in the following chapter. 


\section{Detailed Analysis of Proposed Activity, "Post Express Nonstop" Service}

\subsection{Research Results of Needs and Justifications for "Post Express Nonstop" Service Implementation}

For the purpose of analyzing the interests, needs, and justifications for the new "post express nonstop" service implementation, research was conducted which encompassed the creation of the corresponding questionnaire, collecting of answers from respondents, and their analysis. The formed questionnaire consists of three parts:

- The first part of the questionnaire encompasses questions on the demographic characteristics of respondents;

- The second part of the questionnaire consists of questions which indicate to the profile of a user of express delivery services, i.e., habits of users and attitudes toward the existing post express services;

- The third part of the questionnaire encompasses the questions which, first of all, concern the attitudes toward the proposed "post express nonstop" service.

The questionnaire was created in electronic form and published on the Google platform. The target group of respondents related to the physical and legal entities from the urban city area. Answers were gathered in two manners: individual respondent answering; and interviewing of respondents by researchers, where the obtained answers were inserted into the web-based questionnaire.

Gathered data were statistically analyzed in the software IBM SPSS Statistics v. 21 (Statistical Package for the Social Science). The normality of distribution was tested by using the Kolmogorov-Smirnov test, whereby it was noticed that distributions of continuous variables significantly statistically deviated from the normal distribution. In line with this fact, in further analysis, nonparametric methods were used. For assessment of the connection between certain variables, the Chi-square independence test was used. For testing of differences between two independent groups in relation to a continuous variable, the Mann-Whitney U test was used, while in the case of three or more independent groups, the Kruskal-Wallis test was used [56]. Binary logistic regression was used in order to evaluate the effect of certain independent variables on the possibility for the respondent to be interested in the analyzed service.

The following hypotheses to be investigated may be classified into seven groups. The first group examines if there is a statistically significant difference between users' groups (natural persons/legal entities) regarding the following:

Hypothesis 1 (H1). The number of postal items they send during a year;

Hypothesis $\mathbf{2}$ (H2). The number of postal items they receive during a year;

Hypothesis 3 (H3). Examines if there is a statistically significant connection between types of users (natural persons/legal entities) and the part of the day when they use the service.

The third group of hypotheses examines if there is a statistically significant difference between respondents' groups (natural persons/legal entities) regarding the attitude on the importance of parameter:

Hypothesis 4 (H4). Price, at decision making on the usage of express delivery services;

Hypothesis 5 (H5). A selection of services, at decision making on the usage of express delivery services;

Hypothesis 6 (H6). Security, at decision making on the usage of express delivery services;

Hypothesis 7 (H7). Speed, at decision making on the usage of express delivery services; 
Hypothesis 8 (H8). Time availability, at decision making on the usage of express delivery services;

Hypothesis 9 (H9). Territory and financial availability, at decision making on the usage of express delivery services.

The fourth group consists of hypotheses that examine if there is a statistically significant connection between the type of respondents and the following:

Hypothesis 10 (H10). (Natural persons/legal entities) a need for "post express nonstop" service;

Hypothesis 11 (H11). (Natural persons/legal entities) interest in "post express nonstop" service;

Hypothesis 12 (H12). (Users of post express (PE) services/non-users of PE) and interest in "post express nonstop" service;

Hypothesis 13 (H13). Investigates if there is a statistically significant connection between a need of respondent for "post express nonstop" service, and interest in the same service.

The sixth group of hypotheses examines if there is a statistically significant difference between respondents' groups (defined based on interest in "post express nonstop" service) regarding the following:

Hypothesis 14 (H14). An attitude on importance of parameter-time availability, at decision making on the usage of express items transfer services;

Hypothesis 15 (H15). An attitude on importance of parameter-service selection, at decision making on the usage of express items transfer services;

Hypothesis 16 (H16). A readiness to pay for such service 20\% more than for existing PE services;

Hypothesis 17 (H17). An attitude on the impact of the lower price of "post express nonstop" service in comparison to standard PE services.

The seventh group of hypotheses analyzes a statistically significant difference between respondents' groups (defined based on needs for "post express nonstop" service) regarding the following:

Hypothesis 18 (H18). A preparedness to pay for such service 20\% more than for existing PE services;

Hypothesis 19 (H19). An attitude on the impact of the lower price of "post express nonstop" service in comparison to standard PE services.

Selected Results of the Research

The number of respondents who participated in the survey is 181: $132(72.9 \%)$ natural persons and $49(27.1 \%)$ legal entities. Part of the group of respondents, related to legal entities, consisted mainly of participants in the relevant e-commerce chains. According to this fact, a significant number of legal entities (81.6\%) use some of the existing post express services, while $18.4 \%$ are not users. Out of the total number of natural persons, $78.8 \%$ of them declared themselves as users of post-express services, while in $21.2 \%$, this is not the case. Table 1 shows the representation of the use of existing services by respondents who are users of some of the services of post express service. 
Table 1. Representation of type of post express (PE) services for natural and legal persons.

\begin{tabular}{ccccc}
\hline \multirow{2}{*}{ Respondents } & \multicolumn{2}{c}{ Instant Delivery and Same-Day Delivery } & \multicolumn{2}{c}{ Next-Day Delivery } \\
\cline { 2 - 5 } & No. & $\%$ & No. & $\%$ \\
\hline Natural persons & 13 & $12.5 \%$ & 91 & $87.5 \%$ \\
Legal entities & 3 & $7.5 \%$ & 37 & $92.5 \%$ \\
\hline
\end{tabular}

On the basis of the obtained results, it can be concluded that next-day delivery service has dominant representation in both groups of respondents compared to the services that are being implemented on the same day when they are initiated (instant delivery and same-day delivery).

Table 2 shows the results of an analysis of the frequency of sending the postal items by respondents. The analysis included only respondents who declared themselves as users of the post-express service.

Table 2. Frequency of sending express postal items by natural persons and legal entities.

\begin{tabular}{ccccccccc}
\hline \multirow{2}{*}{ Respondents } & \multicolumn{2}{c}{ At Least Once a Week } & \multicolumn{2}{c}{ At Least Once a Month } & \multicolumn{2}{c}{ At Least Once a Year } & \multicolumn{2}{c}{ Not Sending Postal Items } \\
\cline { 2 - 9 } & No. & $\%$ & No. & $\%$ & No. & $\%$ & No. & $\%$ \\
\hline Natural persons & 3 & $2.9 \%$ & 15 & $14.4 \%$ & 82 & $78.8 \%$ & 4 & $3.8 \%$ \\
Legal entities & 37 & $92.5 \%$ & 2 & $5.0 \%$ & 1 & $2.5 \%$ & 0 & $0.0 \%$ \\
\hline
\end{tabular}

The results indicate that the largest percentage $(78.8 \%)$ of users (natural persons) stated that they send express postal items at least once a year, while $3.8 \%$ of the users of the express delivery service declared that they do not use the service as senders. A total of $92.5 \%$ of legal entities, users of express delivery services, use this service as senders at least once a week.

Table 3 shows results that represent the frequency of the use of express delivery services by users as recipients.

Table 3. Frequency of receiving express postal items by natural persons and legal entities.

\begin{tabular}{ccccccccc}
\hline \multirow{2}{*}{ Respondents } & \multicolumn{2}{c}{ At Least Once a Week } & \multicolumn{2}{c}{ At Least Once a Month } & \multicolumn{2}{c}{ At Least Once a Year } & \multicolumn{3}{c}{ Not Receiving Postal Items } \\
\cline { 2 - 9 } & No. & $\%$ & No. & $\%$ & No. & $\%$ & No. & $\%$ \\
\hline Natural persons & 2 & $1.9 \%$ & 19 & $18.3 \%$ & 81 & $77.9 \%$ & 2 & $1.9 \%$ \\
Legal entities & 23 & $57.5 \%$ & 14 & $35 \%$ & 2 & $5 \%$ & 1 & $2.5 \%$ \\
\hline
\end{tabular}

By analyzing the results, it can be concluded that the largest percentage $(77.9 \%)$ of natural persons (users of the express delivery service) stated that they receive the postal items at least once a year, while $1.9 \%$ of them do not use the service as recipients. More than half $(57.5 \%)$ of legal entities, users of express delivery services, use the service as recipients at least once a week. There is a significant segment $(35 \%)$ of those who use the services as recipients once a month. $2.5 \%$ of legal entities, users of the express delivery service, do not use the service as recipients. Table 4 shows descriptive statistics on the number of sent and received items by natural persons and legal entities in 2018.

Table 4. Descriptive statistics for the number of sent and received postal items by natural persons and legal entities in 2018.

\begin{tabular}{cccc}
\hline Respondents & Activity & Mean & Standard Deviation \\
\hline \multirow{2}{*}{ Natural persons } & Sent & 3.33 & 3.39 \\
& Received & 5.07 & 4.28 \\
\hline \multirow{2}{*}{ Legal entities } & Sent & 855.38 & 1447.65 \\
& Received & 122.63 & 165.18 \\
\hline
\end{tabular}

In 2018, the average natural person sent around three, and received about five, postal items, while the same indicators for legal entities amounted to about 855 and 123, respectively. It can be concluded 
that natural persons receive a higher number of items than they send, while for legal entities, the situation is reversed, and there are considerably more sent items.

It should be noted that there are natural persons who receive/send items and that there are legal entities that only send items. Mann-Whitney U Test results show that there is a statistically significant difference between the groups of respondents (natural persons/legal entities) in relation to the number of send-outs during the year $(Z=-9.307 ; p<0.001)$. The same test showed a statistically significant difference between groups of respondents (natural persons/legal entities) in relation to the number of postal items received during the year $(Z=-8.636 ; p<0.001)$. Based on the above results, $\mathrm{H} 1$ and $\mathrm{H} 2$ are adopted. The following table (Table 5 ) shows the representation of the period of use of the service during the day by natural and legal persons. The results of the Chi-square test $(\chi 2=2.157 ; p=0.340$ ) show that there is no statistically significant link between the type of user (natural persons/legal entities) and the parts of the day in which they use the service. In line with the above, H3 is discarded. Natural persons use the service more in the morning and in the afternoon, which may be influenced by their working hours. On the other hand, for legal entities, the use of the service is approximately uniformly represented in the considered parts of the day.

Table 5. Representation of the period of use of the service during the day by natural and legal persons.

\begin{tabular}{ccccccc}
\hline \multirow{2}{*}{ Respondents } & \multicolumn{2}{c}{ Before Noon } & \multicolumn{2}{c}{ About Noon } & \multicolumn{2}{c}{ Afternoon } \\
\cline { 2 - 7 } & No. & $\%$ & No. & $\%$ & No. & $\%$ \\
\hline Natural persons & 35 & $33.7 \%$ & 24 & $23.1 \%$ & 45 & $43.3 \%$ \\
Legal entities & 12 & $30.0 \%$ & 14 & $35.0 \%$ & 14 & $35.0 \%$ \\
\hline
\end{tabular}

Table 6 shows the mean values of the significance of the parameters per group of respondents when deciding on the use of express delivery services. The relevance is defined by the appropriate scale of five levels (from 1-irrelevant to 5-very important).

Table 6. Mean values of the assessment of the importance of parameters to natural persons and legal entities.

\begin{tabular}{ccccccc}
\hline Respondents & Price & Service Selection & Security & Speed & Time Availability & Territory and Financial Availability \\
\hline Natural persons & 3.92 & 3.75 & 4.64 & 4.57 & 4.33 & 4.10 \\
Legal entities & 4.49 & 3.76 & 4.80 & 4.63 & 4.47 & 3.90 \\
\hline
\end{tabular}

If we look at both groups of respondents in parallel, the following parameters are especially important: price, security, speed, and time availability. The remaining two parameters are also important for respondents when deciding on the use of express delivery services. The respondents from the group legal entities gave something more prominent to the price parameter. The results of the Mann-Whitney U Test $(Z=-3.915 ; p<0.001)$ confirm that there is a statistically significant difference in the groups of respondents (natural and legal persons) in the attitude about the importance of the price parameter. This phenomenon can be explained by the commercial orientation of legal entities and their aspiration to reduce costs, that is, to make greater profits. The results of the same test show that there is no statistically significant difference between the groups of respondents (individuals and legal entities) in the attitude about the importance of all other parameters individually (selection of services $(Z=-0.292 ; p=0.770)$; safety $(Z=-1.578 ; p=0.115)$; speed $(Z=-0.008 ; p=0.994)$; time availability $(Z=-0.331 ; p=0.741)$; territorial and financial availability $(Z=-1.630 ; p=0.103)$. In accordance with the obtained results, $\mathrm{H} 4$ is adopted, while $\mathrm{H} 5, \mathrm{H} 6, \mathrm{H} 7, \mathrm{H} 8$, and $\mathrm{H} 9$ are rejected. The results presented in the following table (Table 7) refer to the respondents' need for sending/receiving of out-of-hours deliveries of the PE service in the previous year (from 7 p.m. to 8 a.m. on weekdays or weekends from 3 p.m. (Saturday) to 8 a.m. (Monday). 
Table 7. Natural persons' and legal entities' need for the "post express nonstop" service in the previous year.

\begin{tabular}{ccccccccc}
\hline \multirow{2}{*}{ Respondents } & \multicolumn{2}{c}{ No } & \multicolumn{2}{c}{ Once } & \multicolumn{2}{c}{ 2 or 3 Times } & \multicolumn{2}{c}{ 4 Times or More } \\
\cline { 2 - 9 } & No. & $\%$ & No. & $\%$ & No. & $\%$ & No. & $\%$ \\
\hline Natural persons & 63 & $47.7 \%$ & 34 & $25.8 \%$ & 30 & $22.7 \%$ & 5 & $3.8 \%$ \\
Legal entities & 11 & $22.4 \%$ & 4 & $8.2 \%$ & 14 & $28.6 \%$ & 20 & $40.8 \%$ \\
\hline
\end{tabular}

Results of the Chi-squared test $(\chi 2=46.829 ; p<0.001)$ show that there is a statistically significant link between the need for out-of-hours PE service and the type of respondents (natural persons/legal entities). In line with the above, H10 is adopted. A little less than half the number of natural persons $(47.7 \%)$ did not have the need for such a service, compared to legal entities, where this indicator is only $22.4 \%$. Of all the natural persons who had the need for this service in the previous year, the highest number are those who only needed it once, while most legal entities (40.8\%) needed to use this service four times or more. One of the reasons for the dependence may be the fact that legal entities would be able to provide services of this type outside their working hours in order to reduce the negative impacts on the efficiency of doing their primary business activities. There are numerous examples that support this, and one of them can be a store that offers its products in retail and electronically. In line with orders via an e-commerce system, certain products must be sent to customers. The seller is limited by the working hours of the courier service (which largely corresponds to the retail time of the retailer) and is obliged to forward the products for transfer at a certain time interval, which can cause negative consequences for the retail business. Depending on the case, sending a product for transport can take place the next day, which can consequently cause a delay in the delivery of the product to a user's address. These entities may find it more convenient for products sold through the e-commerce system to be forwarded for transport before or after the working time of their retail store. Moreover, products ordered before or during the weekend can be shipped in the shortest period, without waiting for the first day of the courier service. Table 8 shows the results related to respondents interest (divided into four groups: natural persons, legal entities, PE users, and non-PE users) for the use of express delivery services ("post express nonstop") outside PE service hours.

Table 8. Interest of natural persons and legal entities for the service "post express nonstop".

\begin{tabular}{ccccc}
\hline \multirow{2}{*}{ Respondents } & \multicolumn{2}{c}{ Yes } & \multicolumn{2}{c}{ No } \\
\cline { 2 - 5 } & No. & $\%$ & No. & $\%$ \\
\hline Natural persons & 85 & $64.4 \%$ & 47 & $35.6 \%$ \\
Legal entities & 36 & $73.5 \%$ & 13 & $26.5 \%$ \\
\hline
\end{tabular}

When the interest in the "post express nonstop" service is analyzed at the level of groups of natural persons and legal entities, it is concluded that, on this matter, a significant part of both of them has a positive attitude ( $64.4 \%$ and $73.5 \%$, respectively). Based on the results of the Chi-squared test $(\chi 2=0.950 ; p=0.330)$, it can be concluded that there is no statistically significant link between the type of respondents (natural persons/legal entities) and the interest in the service. Based on these facts, H11 is rejected.

The results of the Chi-square test $(\chi 2=19.349 ; p<0.001)$ show that there is a statistically significant link between the type of respondents (PE service users/non-PE users) and interest in the "post express nonstop" service. On this basis, H12 is adopted. Namely, a significant percentage (75\%) of PE service users is interested in the "post express nonstop" service, while respondents who do not use express delivery services are interested in a smaller, but still significant, measure (35.1\%) for the analyzed service (Table 9). 
Table 9. Interests of respondents (PE users/not PE users) for "post express nonstop" service.

\begin{tabular}{ccccc}
\hline \multirow{2}{*}{ Respondents } & \multicolumn{2}{c}{ Yes } & \multicolumn{2}{c}{ No } \\
\cline { 2 - 5 } & No. & $\%$ & No. & $\%$ \\
\hline PE users & 108 & $75.0 \%$ & 36 & $25.0 \%$ \\
Not PE users & 13 & $35.1 \%$ & 24 & $64.9 \%$ \\
\hline
\end{tabular}

The results presented in the following table (Table 10) relate to the link between the respondents' need for the "post express nonstop" service and their interest in using it.

Table 10. Correlation between frequency of need and interest in using "post express nonstop" service.

\begin{tabular}{ccccc}
\hline \multirow{2}{*}{ Needs } & \multicolumn{2}{c}{ Yes } & \multicolumn{2}{c}{ No } \\
\cline { 2 - 5 } & No. & \% & No. & $\%$ \\
\hline None & 26 & $35.1 \%$ & 48 & $64.9 \%$ \\
Once & 34 & $89.5 \%$ & 4 & $10.5 \%$ \\
2 or 3 times & 38 & $86.4 \%$ & 6 & $13.6 \%$ \\
4 times or more & 23 & $92.0 \%$ & 2 & $8.0 \%$ \\
\hline
\end{tabular}

Results of the Chi-square test $(\chi 2=57.060 ; p<0.001)$ show that there is a statistically significant correlation between the need for the "post-express nonstop" service and the interest in the same service. Based on this, H13 is adopted. In essence, a large percentage of the respondents who had any need for service was interested in that service, while the majority of those who did not have a need for service was not interested in it.

Table 11 shows the results of the analysis of the respondents' views on the "post express nonstop" service in relation to the views on the following alternatives: (a) importance of the parameter-time availability when deciding on the use of the PE service; (b) importance of the parameter-selection of services, when deciding on the use of the PE service; (c) readiness of the users to pay $20 \%$ more for such a service than for the existing PE services; (d) claims: lower price of the "post express nonstop" service in relation to the standard PE services would motivate potential users to use it. The relevance is defined by the appropriate scale of five levels (from 1-irrelevant to 5-very important). Readiness to pay more is also defined on a scale of five levels of value, where 1 corresponds to the phrase "completely not ready" and 5 is "completely ready". Levels of agreement with a claim concerning lower prices and motivations for using the service are defined on a scale of the same structure, with the value 1 corresponding to the "I completely disagree" and 5 to "I completely agree".

Table 11. Mean value of defined alternatives according to the interest groups for the service.

\begin{tabular}{ccccc}
\hline Interest & $\mathbf{a}$ & $\mathbf{b}$ & $\mathbf{c}$ & $\mathbf{d}$ \\
\hline Yes & 4.50 & 3.86 & 3.40 & 4.43 \\
No & 4.12 & 3.53 & 1.92 & 3.27 \\
\hline
\end{tabular}

The results of Mann-Whitney $\mathrm{U}$ test $(Z=-2.042 ; p=0.041)$, confirm that there is a statistically significant difference in the groups of respondents (interested and not interested in the "post express nonstop" service) in the attitude about the importance of the parameter-time availability when making a decision about the use of the PE service (alternative a). Namely, respondents interested in the stated service find the parameter of time availability more important, than those who are not interested in the same service. The results of the Mann-Whitney U Test $(Z=-2,167 ; p=0.03)$, indicate a statistically significant difference in the same groups of respondents in the attitude about the importance of the parameter-a selection of services when deciding on the use of the PE service (alternative b). The respondents interested in this service value more the parameter of the choice of services than those who are not interested in it. Based on the results above, H14 and H15 are adopted. 
The results of Mann-Whitney U Test $(Z=-6.769 ; p<0.001)$ show there is a statistically significant difference between the interested and the uninterested respondents for the analyzed service, and in their attitude about the willingness to pay $20 \%$ more for the existing ones PE services (alternative c). The respondents who are interested are also more willing to pay higher rates of service, compared to those who are not interested. The results of Mann-Whitney U Test $(Z=-6.902 ; p<0.001)$ show there is a statistically significant difference between the interested and the uninterested respondents for the service under consideration, in their view of the claim that a lower price of services can motivate potential users to use it (alternative d). The people who are interested in the service agree more with this claim; however, there is a considerable agreement by the non-interested ones. This means that this group of potential users can be influenced by a lower price mechanism in order to become interested in the service. Based on the above results, H16 and H17 are adopted.

The stated financial scenarios for the "post express nonstop" service (higher and lower service prices, respectively alternatives $c$ and $d$ ) were further analyzed in relation to the needs of the respondents for the service in the previous year and the appropriate conclusions were drawn (Table 12).

Table 12. Mean value of the estimated alternatives by groups of service needs in the previous year.

\begin{tabular}{ccc}
\hline Needs & $\mathbf{c}$ & $\mathbf{d}$ \\
\hline None & 2.31 & 3.55 \\
Once & 3.42 & 4.34 \\
2 or 3 times & 3.25 & 4.30 \\
4 times or more & 3.32 & 4.60 \\
\hline
\end{tabular}

From the analysis of the results of the Kruskal-Wallis test, a statistically significant difference between the groups defined by the need for the "post express nonstop" service in the attitude toward the alternatives $c-(\chi 2=23.559 ; p<0.001)$ and $d-(\chi 2=33.278 ; p<0.001)$. Respondents who had the need for the analyzed service expressed greater readiness to pay more for it. Based on the above, it is concluded that $\mathrm{H} 18$ and $\mathrm{H} 19$ are adopted.

It is interesting to note that respondents who had a need to use the service once (group 2) were more willing to pay more than those who had the same need four times or more (group 4). The reason for this may be the fact that the fourth group is largely owned by legal entities, who are market-oriented and for whom cost-cutting, that is, the increase in profits is of great importance. Natural persons, who mostly make up the second group, when considering the financial aspect of the service, take into account that they were in need of the service only a few times (once) in the previous year, so paying for the service at a higher price would not pose a problem at such a frequency of use. Respondents who needed to use the service are more likely to agree with the claim that the lower price of services would further motivate them to use it. It is important to note here that those respondents who did not have the need for this service considerably agree with the indicated effect of motivation. This fact can be used to create a mechanism that will attract users.

Data processing also carried out logistic regression to determine how well a defined set of predictor variables predicts or explains the categorical dependent variable [56]. A preliminary model with a dependent variable was established: Participants' interest in the "post express nonstop" service; and independent variables: User group (natural persons / legal entities); The most frequently used PE service; Part of the day when the service is the most often used; Importance of the time availability parameter when deciding on the use of the express delivery service; Importance of the parameter selection of services when deciding on the use of the express delivery service; Need for "post express nonstop" service. The preliminary model, which includes the previously mentioned variables, has a greater predictive power than the zero model, and this difference is statistically significant $(\chi 2=69.343$; $d f=10 ; p<0.001, R_{N}^{2}=44.2 \%$ ). The final model consists only of variables that have been statistically significant and accurately classify $78.5 \%$ of cases. The obtained model has a higher predictive power than the zero model and the difference is statistically significant $(\chi 2=65.554 ; d f=4 ; p<0.001$, 
$R_{N}{ }^{2}=42.2 \%$ ). The variables (predictors) included in the final model with corresponding characteristics (odds ratio, 95\% confidence interval (CI), and $p$-value) are shown in Table 13.

Table 13. Characteristics of variables (predictors) included in the final model.

\begin{tabular}{llc}
\hline \multicolumn{1}{c}{ Variables } & \multicolumn{1}{c}{ Interest in the "Post Express Nonstop" Service } \\
\cline { 2 - 3 } & Odds Ratio (95\% CI) & $p$-Value \\
\hline $\begin{array}{l}\text { Need for "post express nonstop" service (reference } \\
\text { group—respondents who did not have a need for } \\
\text { a service) }\end{array}$ & & \\
\hline - once & $17.263(5.363-55.569)$ & $0.000^{*}$ \\
\hline - 2 or 3 times & $14.062(5.026-39.348)$ & $0.000^{*}$ \\
\hline - 4 times or more & $14.062(5.026-39.348)$ & $0.000^{*}$ \\
\hline $\begin{array}{l}\text { The importance of the parameter-service selection, at } \\
\text { decision making on the use of express services }\end{array}$ & $1.707(1.101-2.628)$ & 0.017 \\
\hline
\end{tabular}

The results show that for those potential users who had the need for the "post express nonstop" service 4 times or more in the past year, there is a 20.101-fold chance to find themselves in a group of people interested in the same service compared to those who did not have any need for it.

Following are the potential users who had the need for the service once (17.263 times more chance to find themselves in the group of people interested in the service compared to those who did not need it); those who had the need for it two or three times during the year (14.062 times higher the chance to find themselves in a group of people interested in the service in relation to those who did not need it). On the other hand, every single increase in the importance of the parameter-the choice of services, with the potential user, shows 1.707 times more chance of being interested in the "post express nonstop" service.

The main aim of the research was to investigate the respondents' habits and attitudes about the existing express delivery services, as well as their interest and need for a new service that was proposed in the paper. Market research is a necessary step in the chain of activities that precede the introduction of new or modification of existing services. The results obtained in this way represent a good basis for the formation of a strategy aimed at proposing a new service or modifying an existing one. When introducing a new express delivery service, the company management should take into account its sustainability in the market. This entails attracting a certain number of customers, that is, postal items, which will make a satisfactory profit. The results of the research can indicate a number of facts and corresponding changes in the habits and needs of society, which need to be addressed through the characteristics of the new service. Accordingly, it is possible to define the target group of users, the concept of the service, as well as activities that can contribute to its better acceptance by users.

In addition, in this paper, relevant research results, primarily related to the interest of certain groups of respondents in the new service, were used to obtain one of the input parameters (correction factor, $\Delta c$, in Section 4.2.3) of the proposed modified Bass model for forecasting the number of postal items. Namely, within the statistical analysis, apart from the interest of all respondents (scenario I), by appropriately crossing the collected answers, the opinions on the interest of respondents who are users of the existing express parcel transfer services (scenario II) were singled out. In addition, the impact of the increase (scenario III) and decrease (scenario IV) of the price of the new service on the respondents' interest in it was explored. By incorporating the impact of the aforementioned research results into the proposed modified Bass model, four different scenarios were obtained, which allows one to see a broader picture of acceptance of a new service in the future. 


\subsection{The Postal Items Forecasting for the "Post Express Nonstop" Service for the Period from 2020 to 2025}

Successful implementation of the Bass model is in direct correlation with the successful assessment of innovation and imitation parameters. The parameters can be determined before or after the service is introduced, and the relevant methods are presented below [57,58]

An appropriate approach for determining the parameters before introducing a service is to apply market research methods, such as Delphi Method, Survey Method, Comparison Method, Brainstorming, and Analog analysis and connection.

To determine the parameters after the introduction of the service, the following mathematical techniques are appropriate:

- Maximum Likelihood Estimation (MLE);

- Ordinary Least Squares (OLS);

- Nonlinear Least Squares (NLS);

- Algebraic Method.

When defining the parameters $\mathrm{p}$ and $\mathrm{q}$ in this case, an analogy with the number of express postal items in the public company The Post of Serbia was used. Table 14 shows the number of these items from the Universal Postal Union (UPU) statistics, for the period from January 2003 to December 2017. The Post of Serbia has been offering express delivery services since 2002.

Table 14. The number of express postal items in The Post of Serbia.

\begin{tabular}{cc}
\hline Year & The Number of Express Postal Items \\
\hline 2003 & 205,481 \\
2004 & 516,243 \\
2005 & 783,702 \\
2006 & $1,262,334$ \\
2007 & $1,950,128$ \\
2008 & $2,632,730$ \\
2009 & $2,717,231$ \\
2010 & $3,233,102$ \\
2011 & $4,020,254$ \\
2012 & $4,799,189$ \\
2013 & $5,467,375$ \\
2014 & $5,664,297$ \\
2015 & $6,493,458$ \\
2016 & $7,591,981$ \\
2017 & $8,413,733$ \\
\hline
\end{tabular}

Source: http://www.upu.int/en/resources/postal-statistics/about-postal-statistics.html.

In this example, the method of the least squares was used as the mathematical technique for determining the parameters $p$ and $q$, since it was proved to be one of the simplest. By applying this technique to a regression analogy for the basic Bass model, the following target function is obtained:

$$
S(a, b, c)=\sum_{t=1}^{n}\left(s_{t}-a-b N_{t-1}-c N_{t-1}^{2}\right)^{2}
$$

where $a, b, c$ are regression parameters, determined through minimizing conditions $\left(\frac{d S}{d a}=0, \frac{d S}{d b}=0\right.$ and $\left.\frac{d S}{d c}=0\right)$ of the target function. A system of three linear equations is formed, with three unknowns $a, b$, and $c$. By solving this system, the values of the regression parameters are obtained, and they represent a basis to calculate the values of the parameters of innovation $(p)$ and imitation $(q)$ :

$$
p=\frac{-b+\sqrt{b^{2}-4 a c}}{2}, q=\frac{b+\sqrt{b^{2}-4 a c}}{2}
$$


The system of three linear equations with three unknowns is as follows:

$$
\begin{gathered}
a n+b \sum_{t=1}^{n} N_{t-1}+c \sum_{t=1}^{n} N_{t-1}^{2}=\sum_{t=1}^{n} S_{t} . \\
a \sum_{t=1}^{n} N_{t-1}+b \sum_{t=1}^{n} N_{t-1}^{2}+c \sum_{t=1}^{n} N_{t-1}^{3}=\sum_{t=1}^{n} S_{t} N_{t-1} \\
a \sum_{t=1}^{n} N_{t-1}^{2}+b \sum_{t=1}^{n} N_{t-1}^{3}+c \sum_{t=1}^{n} N_{t-1}^{4}=\sum_{t=1}^{n} S_{t} N_{t-1}^{2}
\end{gathered}
$$

Table 15 shows the values necessary for determining the regression parameters, and it indirectly shows the Bass model parameters. By solving the system of linear Equation (7), the following values of the regression parameters are obtained: $a=0.828, b=0.253$, and $c=-0.002$. Based on these values and

\begin{tabular}{|c|c|c|c|c|c|c|c|c|}
\hline$T$ & Year & $s_{t}$ & $N_{(t-1)}$ & $N_{(t-1)}^{2}$ & $N_{(t-1)}^{3}$ & $N_{(t-1)}^{4}$ & $s_{t} N_{(t-1)}$ & $s_{t} N_{(t-1)}^{2}$ \\
\hline 1 & 2003 & 0.205 & 0.000 & 0.000 & 0.000 & 0.000 & 0.000 & 0.000 \\
\hline 2 & 2004 & 0.516 & 0.205 & 0.042 & 0.009 & 0.002 & 0.106 & 0.022 \\
\hline 3 & 2005 & 0.784 & 0.722 & 0.521 & 0.376 & 0.271 & 0.566 & 0.408 \\
\hline 4 & 2006 & 1.262 & 1.505 & 2.266 & 3.412 & 5.136 & 1.900 & 2.861 \\
\hline 5 & 2007 & 1.950 & 2.768 & 7.660 & 21.202 & 58.683 & 5.397 & 14.939 \\
\hline 6 & 2008 & 2.633 & 4.718 & 22.258 & 105.013 & 495.439 & 12.421 & 58.601 \\
\hline 7 & 2009 & 2.717 & 7.351 & 54.032 & 397.166 & 2919.412 & 19.973 & 146.816 \\
\hline 8 & 2010 & 3.233 & 10.068 & 101.362 & 1020.493 & $10,274.171$ & 32.550 & 327.712 \\
\hline 9 & 2011 & 4.020 & 13.301 & 176.915 & 2353.142 & $31,299.022$ & 53.473 & 711.244 \\
\hline 10 & 2012 & 4.799 & 17.321 & 300.024 & 5196.780 & $90,014.486$ & 83.128 & 1439.873 \\
\hline 11 & 2013 & 5.467 & 22.120 & 489.312 & $10,823.770$ & $239,426.068$ & 120.940 & 2675.251 \\
\hline 12 & 2014 & 5.664 & 27.588 & 761.085 & $20,996.637$ & $579,250.375$ & 156.265 & 4311.011 \\
\hline 13 & 2015 & 6.493 & 33.252 & 1105.700 & $36,766.806$ & $1,222,572.254$ & 215.921 & 7179.816 \\
\hline 14 & 2016 & 7.592 & 39.746 & 1579.707 & $62,786.270$ & $2,495,473.189$ & 301.747 & $11,993.103$ \\
\hline 15 & 2017 & 8.414 & 47.338 & 2240.839 & $106,075.745$ & $5,021,361.125$ & 398.285 & $18,853.824$ \\
\hline \multicolumn{2}{|c|}{$\Sigma$} & 55.751 & 228.002 & 6841.724 & $246,546.820$ & $9,693,149.634$ & 1402.674 & $47,715.482$ \\
\hline
\end{tabular}
Equation (6), the innovation parameter is $p=0.006$, and the imitation parameter is $q=0.259$.

Table 15. Values for calculating regression parameters.

\subsubsection{Calculating Market Potential for the "Post Express Nonstop" Service}

Market potential includes all potential users of services [32]. There are different ways to define it and in accordance with different parameters. In the observed case, the existing express delivery market in the Republic of Serbia is taken as the market potential. Forecasting the number of postal items for the "post express nonstop" service is done for the period from 2020 to 2025. Therefore, it is essential to determine the market potential for this time period, which implies forecasting the number of express postal items. The prognosis was made based on the observed linear trend (Figure 1). 


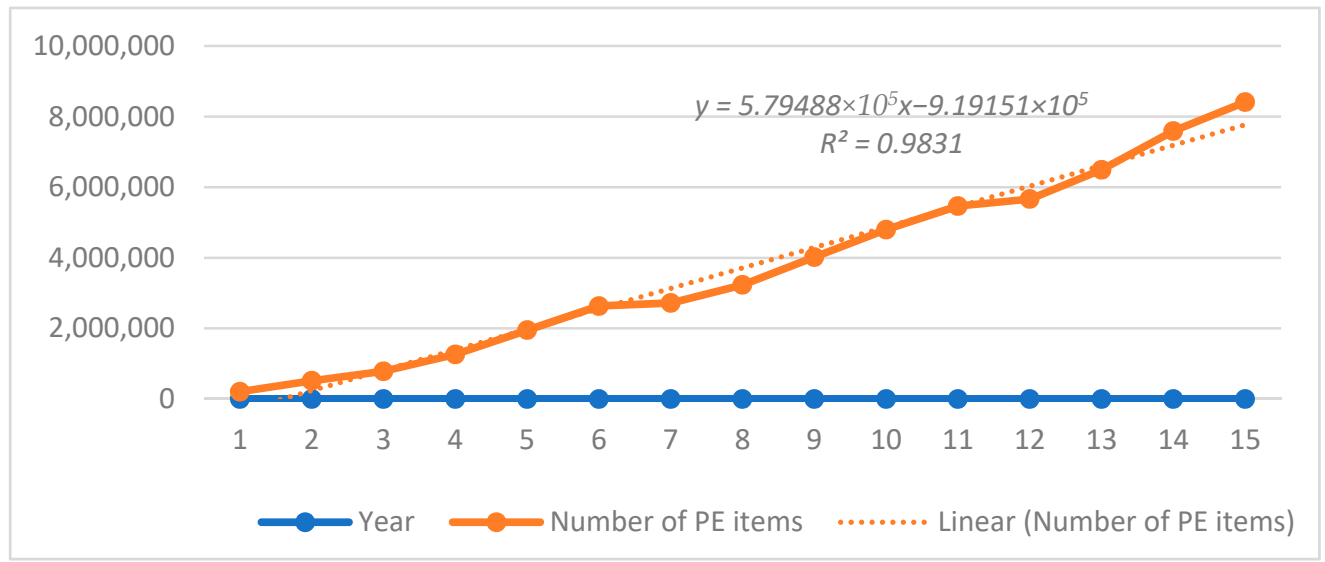

Figure 1. Linear trend of the number of express postal items.

To determine the potential of the market, statistics were used on the number of express items originating from the Universal Postal Union database (see Table 14).

Based on the determination coefficient value $\left(R^{2}=0.9831\right)$, it can be concluded that the data closely describe the indicated trend $\left(y=5.79488 \times 10^{5} x-9.19151 \times 10^{5}\right)$, based on which we obtain the anticipated number of express postal items for the defined time period (Table 16).

Table 16. Forecasted number of post express items from 2020 to 2025.

\begin{tabular}{cc}
\hline Year & Number of Post Express Items \\
\hline 2020 & $9,511,633$ \\
2021 & $10,091,121$ \\
2022 & $10,670,609$ \\
2023 & $11,250,097$ \\
2024 & $11,829,585$ \\
2025 & $12,409,073$ \\
\hline
\end{tabular}

4.2.2. Forecasting the Number of Postal Items for the "Post Express Nonstop" Service from 2020 to 2025

Based on the calculated parameters of innovation and imitation and the relevant potential of the market, the number of deliveries (from 2020 to 2025) for the proposed service "post express nonstop" is estimated and the results are shown in Table 17.

Table 17. Forecasted number (intensity of acceptance) of "post express nonstop" items for the period from 2020 to 2025 .

\begin{tabular}{cc}
\hline Year & Number of “Post Express Nonstop" Items \\
\hline 2020 & $57,069.798$ \\
2021 & $74,901.7913$ \\
2022 & $96,989.72793$ \\
2023 & $124,220.9052$ \\
2024 & $157,601.5731$ \\
2025 & $198,237.2773$ \\
\hline
\end{tabular}

Clearly, in the first year after the service has been introduced, the number of new service postal items depends on the activity of the innovators. In this case, the volume of items is estimated to be approximately 57,069 in the first year, while in 2025 the volume of items will be around 198,237. The cumulative number of items for the given period of time is approximately 709,021 . Figure 2 shows the forecasted cumulative number of "post express nonstop" items for the period from 2020 to 2025. 


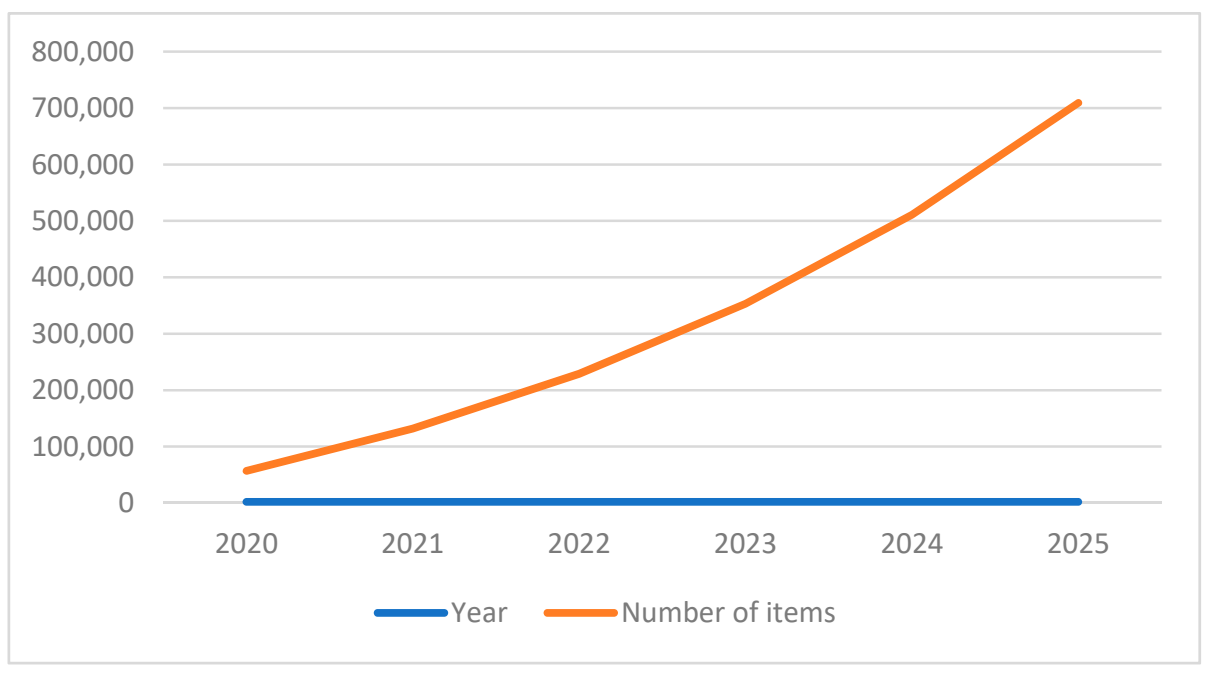

Figure 2. Forecasted cumulative number of "post express nonstop" items (2020-2025).

The impact of different scenarios on accepting the service that is obtained in accordance with the results of the conducted market research is presented below.

4.2.3. Application of the Modified Bass Model in Order to Forecast the Number of Postal Items for "Post Express Nonstop" Service (2020-2025)—Different Scenarios

In accordance with the results of the conducted research presented previously in the chapter, there are four scenarios of the "post express nonstop" service that have been performed. The methodology for performing a scenario is simple and is based on the influence of the corrected factor $(\Delta c)$ on the imitation (q) parameter. Based on the relation (9), we obtain the corrected factor, $\Delta c$.

The influence of the corrected factor $(\Delta c)$ on the innovation parameter $p$ has not been taken into account. The view is that no influence applied to innovators would significantly change their decision to use a new service, unlike imitators.

The first scenario indicates the $\Delta c$ obtained from the results of the survey, whereas a percentage of respondents who were not interested in the new "post express nonstop" service has been taken into account. The percentage of these respondents from the total number of respondents is $33.15 \%$. Therefore, the imitation $(q)$ parameter was adequately reduced. As a result, the corrected factor has the value $\Delta c=0.6685$.

In the second proposed scenario, we observed the views from the group of respondents who declared themselves as users of the existing post express services. A percentage of respondents who were not interested in the new "post express nonstop" service has been taken into account. The percentage of these respondents from the total number of respondents is $25 \%$, therefore the imitation (q) parameter was adequately reduced. Based on this, the corrected factor has the value $\Delta c=0.75$.

The third scenario takes into account the impact of the $20 \%$ increase in the price of the service. A part of the respondents who were not interested in the service (from the first scenario) and those who were interested in the service but who expressed unwillingness to pay a higher price of the service, which was assumed as if they were not interested, was taken into account. The total segment of these groups of respondents is $65.19 \%$, therefore the imitation $(q)$ parameter was adequately reduced. The corrected factor has the value $\Delta c=0.348$.

The fourth scenario takes into account the impact of the reduction of service price by $20 \%$. We have taken into account a part of the respondents who were not interested, as well as those who were interested in the service, but who expressed a negative attitude about being motivated by the lower price of the service, which was assumed as if they were not interested. The total segment of these groups of respondents is $1.11 \%$. The corrected factor has the value $\Delta c=0.9889$. 
The paper discusses four scenarios showing the intensity of acceptance of new service in the next years, which is a significant indicator for management and decision-makers prior to the introduction of the proposed service. Namely, acceptance of a new service depends on many factors, such as the need for and interest in the new service. Therefore, customer acceptance of the service may be of varying volume and pace. For the company, before the introduction of service, it is important to look at different scenarios of acceptance in order to investigate the feasibility and sustainability of the service in the future. Anyhow, the goal of the company is to strive for the most favorable scenario (in this case the scenario with the highest number of postal items); however, it is good to consider the others in order to plan the appropriate strategic activities, if the most favorable scenario is not met. In addition, the analysis of different scenarios of acceptance of the service is of great importance when planning the resources necessary for its smooth and efficient realization.

Analyzing the results obtained through the modified Bass model, through the four considered scenarios (depending on the value of the correction factor, $\Delta c$ ), it can be said that the third scenario is pessimistic and the fourth one is optimistic. Further analysis concluded that the number of postal items forecasted under scenario IV slightly deviates from the number of items projected by the basic Bass model (Table 17). Based on this, we can conclude that the forecasted number of items by the basic Bass model, in this case also belongs to some kind of optimistic scenario. As the optimistic scenario is not always realized in reality, it is necessary to consider modified scenarios, and above all for the aforementioned reason, in order to analyze the feasibility and sustainability of the new service in the future. Table 18 and Figure 3 show the obtained forecasted results for each of the proposed scenarios.

Table 18. Forecasted number (intensity of acceptance) of "post express nonstop" postal items for the period from 2020 to 2025 - four scenarios.

\begin{tabular}{ccccc}
\hline Year & Scenario I & Scenario II & Scenario III & Scenario IV \\
\hline $\mathbf{2 0 2 0}$ & $57,069.798$ & $57,069.798$ & $57,069.798$ & $57,069.798$ \\
$\mathbf{2 0 2 1}$ & $70,029.57532$ & $71,227.42027$ & $65,320.50142$ & $74,738.64922$ \\
$\mathbf{2 0 2 2}$ & $85,005.11473$ & $87,875.96085$ & $74,197.20105$ & $96,575.24221$ \\
$\mathbf{2 0 2 3}$ & $102,259.6641$ & $107,388.304$ & $83,735.26029$ & $123,437.5959$ \\
$\mathbf{2 0 2 4}$ & $122,074.375$ & $130,168.8433$ & $93,969.98943$ & $156,296.8932$ \\
$\mathbf{2 0 2 5}$ & $144,743.7156$ & $156,646.4911$ & $104,936.2716$ & $196,218.5906$ \\
\hline
\end{tabular}

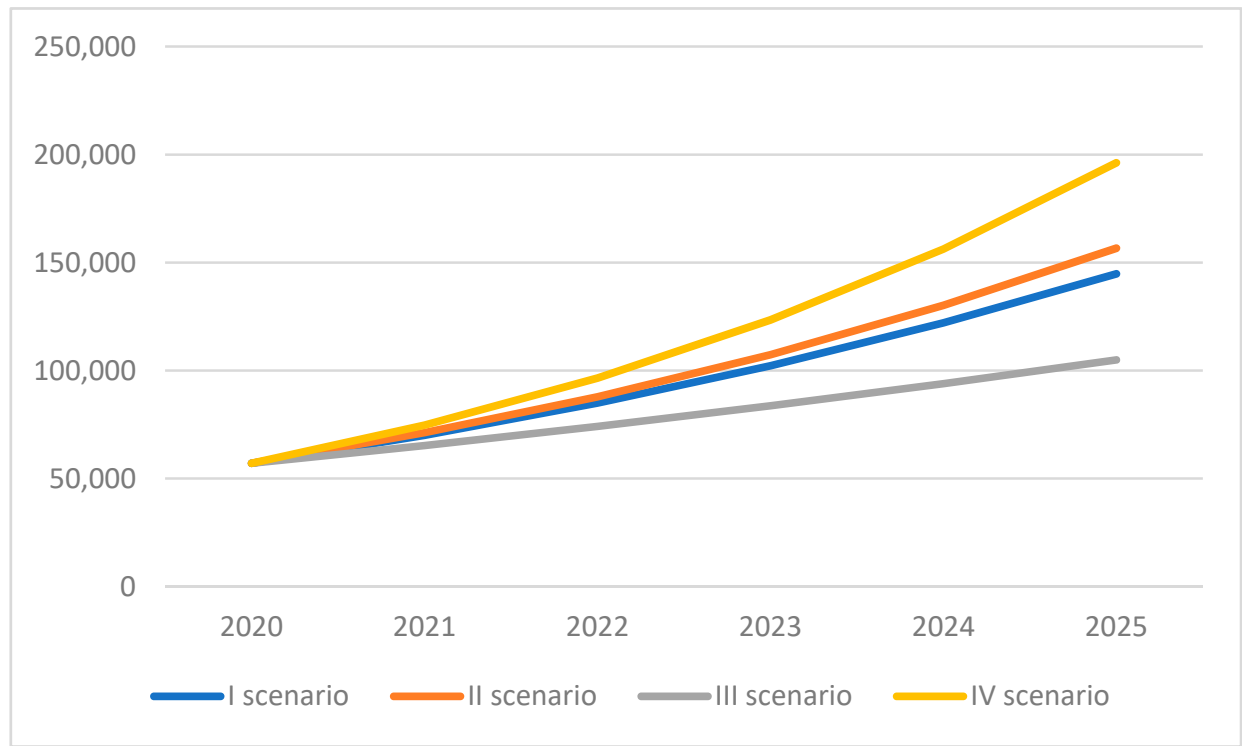

Figure 3. Graphic illustration of the intensity of acceptance of "post express nonstop" postal items from 2020 to $2025-4$ scenarios. 
The express delivery system is the company's most profitable segment, which together with its continuous optimization contributes to reaching a positive attitude about the economic justification of introducing the new service. In addition to the above presented scenarios, new ones can be created as well and then the most suitable for both users and the company can be chosen. Not taking into account the financial aspect, introduction of the "post express nonstop" service can contribute to improving the company's brand and expanding the market. In this way, the company would become a pioneer in offering express delivery services outside of standard working hours.

\section{Analysis of the Impact of the New "Post Express Nonstop" Service on $\mathrm{CO}_{2}$ Emissions}

The impact of human activities on the environment, due to its global importance, is an extremely significant topic today. One of the biggest negative impacts of human activities is the greenhouse gas emissions resulting from the combustion of fuel in transport. The major contributor to emissions is $\mathrm{CO}_{2}$ and the largest proportion comes from road transport. Postal and courier companies carry out their transport activities in domestic traffic mostly within the framework of road transport.

Traffic in daily urban conditions is characterized by frequent traffic congestions and slowed traffic flow due to network load, which has a significant impact on the efficiency of its functioning and on the fuel consumption. Frequent stops, starting the vehicle from standstill, driving in lower gears at high engine speed are the basic characteristics of city traffic functioning, as well as factors that contribute to a significant increase in fuel consumption. The greenhouse gas emissions are directly related to the fuel consumption. One of the goals of socially responsible companies is to reduce the negative impact on the environment and to promote environmentally responsible business activities. One of the ways to achieve this goal is to reduce fuel consumption.

The introduction of the new express delivery service also implies the transfer of one part of traffic requests from daily traffic conditions (existing services) to evening and night conditions (new service). One of the main features of traffic during the period of the new service performing is the absence of traffic congestion, which primarily enables easier maintenance of constant speed while driving and reducing the number of unnecessary stops (stopping in the vehicle column, etc.). The assumption is that in the evening and night (hereinafter referred to as night) traffic conditions, less fuel would be consumed than in daytime conditions (thus, less $\mathrm{CO}_{2}$ would be emitted) for the same volume of requirements. In order to reach appropriate conclusions and confirm or reject this assumption, an experiment was conducted on the territory of Belgrade. Namely, the delivery of express items within the existing services, as well as within the proposed new "post express nonstop" service, is simulated. In both cases, identical requirements were taken into account.

The research methodology is defined through the following key steps:

- Defining the territory in which the experiment would be carried out, that is, simulating the delivery of express items;

- Analysis of requirements, defining the driving route and periods during the day in which the experiment would take place, as well as its dynamics;

- The departure of the vehicle and simulation of delivery at the specified locations, in accordance with a predetermined route;

- Completion of driving (delivery of express items) and return to the starting point with control of fuel consumption from the moment the vehicle leaves the field;

- Determination of $\mathrm{CO}_{2}$ emissions based on fuel consumption.

The methodology involves the realization of an experiment on the same vehicle, with the same load and tire pressure, by multiple drivers (different driving styles), during the working week. Each driver, on the basis of defined identical requirements and driving route, visits the delivery locations, and after completion, returns to the starting point where fuel consumption is controlled. For the same requirements, the driver simulates the delivery twice more times during the daily shift (existing service) and three more times within the "post express nonstop" service. Accordingly, it is foreseen 
that each driver will drive (simulate delivery) six rides, according to the same requirements and on the identical driving route, only in different parts of the day (three rides in day conditions-existing services; three rides in night conditions-new "post express nonstop" service). It is understood that when making a real delivery, the driver switches off the vehicle's engine upon arrival at the location. In the case of a delivery simulation, drivers reach the location, park, and then continue on to the next location. In order to ensure true results, several drivers, different driving styles, were included in the experiment. Upon completion of the experiment, the total fuel consumption for day conditions (existing services) and night conditions (new "post express nonstop" service) is determined.

In accordance with the obtained fuel consumption and the fact that combusting $1 \mathrm{~L}$ of diesel emits $2640 \mathrm{~g}$ of $\mathrm{CO}_{2}$, the total amount of $\mathrm{CO}_{2}$ emissions is determined [59,60]. Taking into account the average number of requests (postal items) that a courier can deliver under given conditions, the amount of $\mathrm{CO}_{2}$ emissions per item can be defined, within the transport process on delivery. The emissions from other activities (packaging, sorting, etc.) within the technological process of transfer of items are not included.

In this way, it is possible to analyze $\mathrm{CO}_{2}$ emissions for delivery in day conditions (existing services) and night conditions (new "post express nonstop" service), so the impact of the new proposed service on the environment through $\mathrm{CO}_{2}$ emissions can be determined.

\subsection{Implementation of the Proposed Methodology on the Territory of Belgrade}

In the first step of the methodology, the territory in which the survey was conducted is defined. The territory of the municipality of Vozdovac was selected, that is, delivery areas belonging to Postal Unit 48. One of the main criteria for the selection of this particular part of the city is, first of all, its relief, population density and developed transport network, which can be a faithful representation of the whole city.

The second step involves the analysis of realistic requirements and the formation of demands for research purposes. They are shown in the form of a driving route in the area that the courier needs to cross to visit all the necessary locations (Figure 4$)$. This route $(16.3 \mathrm{~km})$ is based on an analysis of realistic requirements and represents the route most often used by couriers in this area. The red marker represents the location of the postal unit, that is, the start and endpoint of the driving route. Passing a defined route, couriers usually visit around 20 locations and deliver an average of 28 items (more than one item is delivered at some locations).

In order to test and control fuel consumption, in addition to the different types of terrain in the city (which allows the relief of the selected territory), different conditions on the traffic flow should be taken into account. Three characteristic time periods were selected for experiment realization (simulating delivery), in day or night conditions:

- In day conditions (existing service): 8 a.m.-10 a.m., 12 a.m.-2 p.m., and 4 p.m.-6 p.m.;

- In night conditions (new service): 8 p.m.-10 p.m., 1 a.m.-3 a.m., and 5 a.m.-7 a.m.

The indicated time periods do not include the delivery time at the location, as it was not of interest to the research objective. Namely, it is understood that the driver, upon arrival at the location, switches off the vehicle's engine and performs delivery, so there is no fuel consumption during this time period. The experiment involved five drivers with different driving styles. Each of them drove for the defined time periods (three terms) in day and night conditions. Care was taken that the same driver, due to fatigue, did not simulate one after the other day and night delivery. The routes and requirements were identical in each term and for each driver. After each end of the ride (upon returning to the starting point), fuel consumption was checked and records kept. 


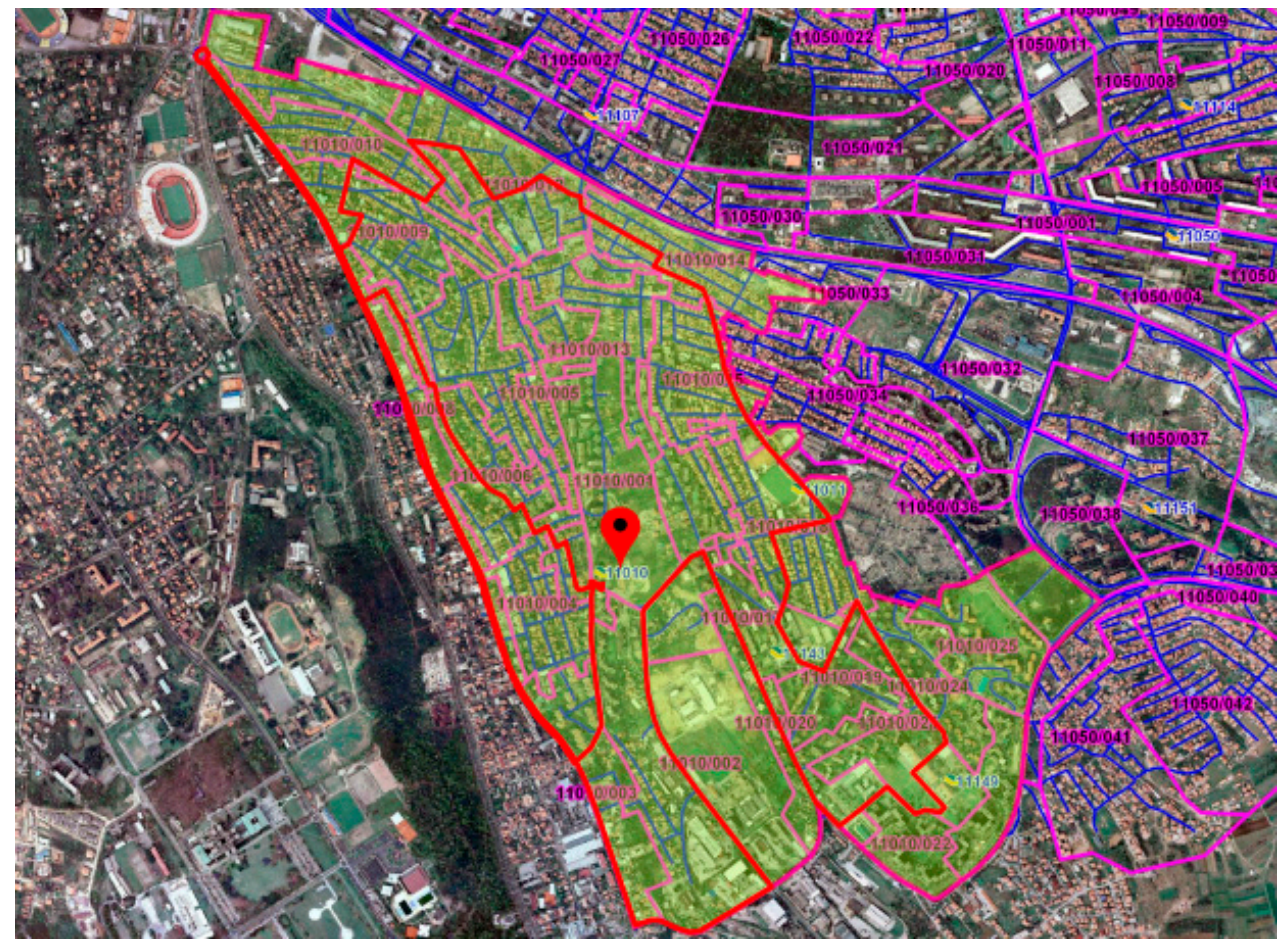

Figure 4. The area and route for the simulation of express postal items' delivery.

One vehicle was used in the experiment-Peugeot Partner $1.6 \mathrm{HDI}$, diesel, the year 2007, $66 \mathrm{~kW}$ (90 PS) with manual transmission and tires for the summer season (in accordance with weather conditions and date of carrying out the experiment). During the delivery simulation, a driver and a researcher were present in the vehicle.

\subsection{The Results of the Experiment}

In the simulation of delivery, as already explained in the methodology, all drivers drove the same vehicle and the same route $(16.3 \mathrm{~km})$ in a day and night conditions, respectively, during defined periods of time (a total of three daytime and three nighttime trips). Table 19 shows the achieved results, that is, the data on average diesel consumption (ADC), when taking into account the rides of all drivers over defined periods of time.

Table 19. Average diesel consumption over defined periods of time.

\begin{tabular}{ccccccc}
\hline \multirow{2}{*}{ Consumption } & \multicolumn{3}{c}{ Day (Existing Service) } & \multicolumn{3}{c}{ Night (New Service) } \\
\cline { 2 - 7 } & $\mathbf{8}$ a.m.-10 a.m. & $\mathbf{1 2}$ a.m.-2 p.m. & 4 p.m.-6 p.m. & $\mathbf{8}$ p.m.-10 p.m. & $\mathbf{1}$ a.m.-3 a.m. & 5 a.m.-7 a.m. \\
\hline ADC (liters) & 1.35942 & 1.2877 & 1.35616 & 1.02364 & 0.95844 & 0.96496 \\
\hline
\end{tabular}

Based on the obtained diesel consumption, $\mathrm{CO}_{2}$ emissions values over the observed time periods were calculated (Figure 5). 


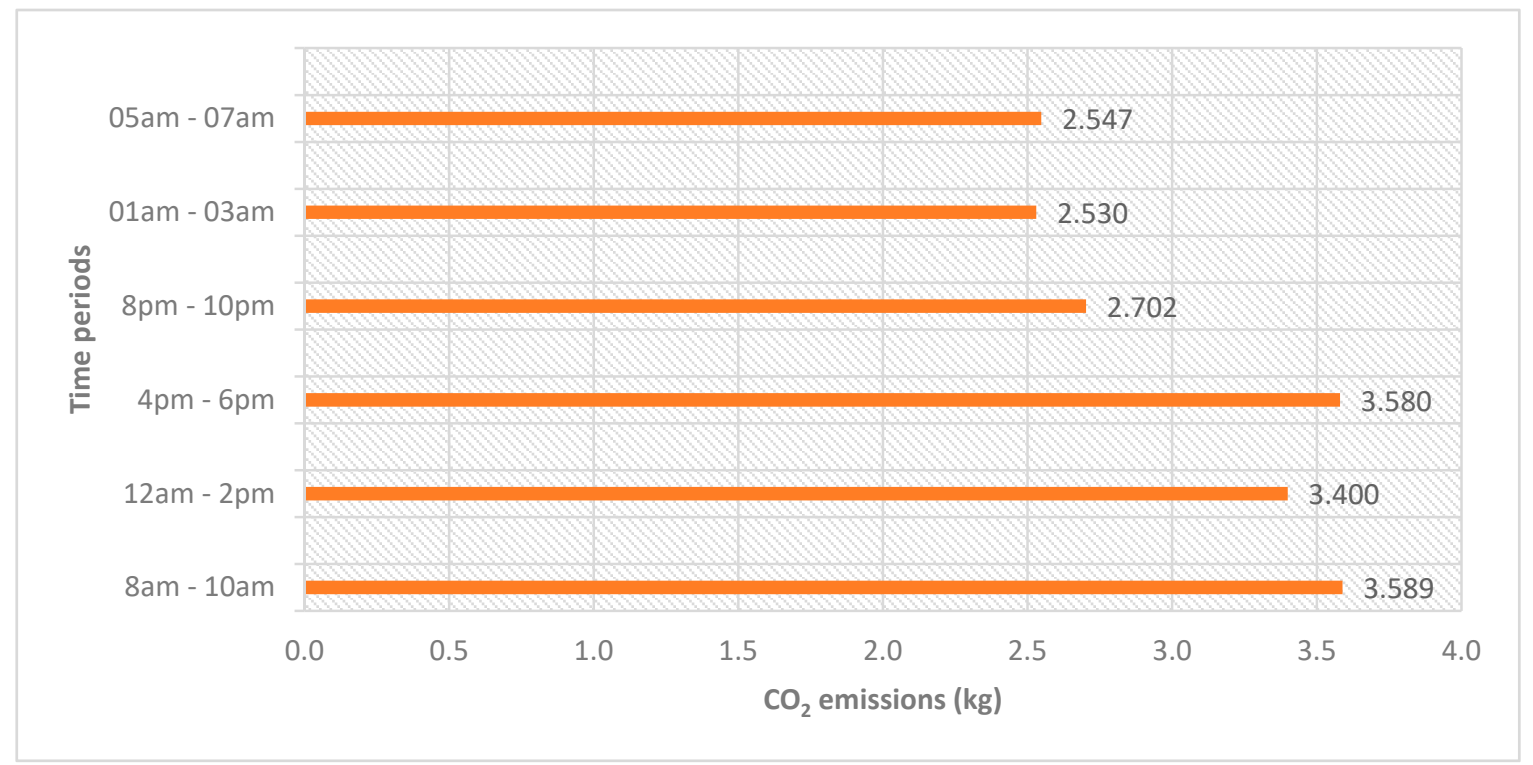

Figure 5. $\mathrm{CO}_{2}$ emissions over the observed time periods.

By analyzing the obtained indicators, it can be concluded that the lowest diesel consumption and emission of $\mathrm{CO}_{2}$ were achieved in the night conditions, in the period from 1 a.m. to 3 a.m., while the highest in the day conditions were from 8 a.m. to 10 a.m. In addition, the periods 5 a.m. -7 a.m., with values of diesel consumption and $\mathrm{CO}_{2}$ emissions close to the minimum, and 4 p.m.- 6 p.m., with values close to the maximum, are distinguished. The obtained results confirm the assumption that, in the night conditions, less fuel would be consumed than in the daily conditions, i.e., that the $\mathrm{CO}_{2}$ emission would be lower, for the same volume of requirements.

Table 20 shows the average values of diesel consumption (average diesel consumption at the level of all time periods-ADC AT) and $\mathrm{CO}_{2}$ emissions (average $\mathrm{CO}_{2}$ emissions at all time periods-AE $\mathrm{CO}_{2} \mathrm{AT}$ ), simultaneously taking into account all three daytime and the three nighttime periods for all drivers. In accordance with these values and the approximate number of items, which is delivered (28 items) with one pass of a defined route, it means that 84 items were delivered in three passes (three daytime periods). The same was adopted for night conditions. Based on these data, average diesel consumption and $\mathrm{CO}_{2}$ emissions were calculated per item delivered (for transport in delivering segment only), both for day (existing service) and night (new service) conditions.

Table 20. Average diesel consumption and $\mathrm{CO}_{2}$ emissions for all periods of time and per items.

\begin{tabular}{cccc}
\hline \multicolumn{2}{c}{ Day (Existing Service) } & \multicolumn{2}{c}{ Night (New Service) } \\
\hline ADC AT (liters) & $\mathrm{AE} \mathrm{CO}_{2}$ AT (kg) & ADC AT (liters) & AE CO $_{2}$ AT (kg) \\
4.00328 & 10.5686592 & 2.94704 & 7.7801856 \\
\hline ADC AT/item & $\mathrm{AE} \mathrm{CO}_{2}$ AT/item & ADC AT/item & AE CO C $_{2}$ AT/item \\
(liters/item) & $\mathbf{( k g / \text { item) }}$ & $\mathbf{( l i t e r s / i t e m ) ~}$ & $\mathbf{( k g / i t e m ) ~}$ \\
0.047658095 & 0.125817371 & 0.03508381 & 0.092621257 \\
\hline
\end{tabular}

ADC AT-average diesel consumption at the level of all time periods; $\mathrm{AE} \mathrm{CO}_{2} \mathrm{AT}$-average $\mathrm{CO}_{2}$ emissions at all time periods.

The analysis of the obtained values leads to the conclusion that the savings according to the mentioned criteria are on the side of night conditions (new service) and amount to about $26 \%$ compared to day conditions (existing service).

The obtained values of average diesel consumption and $\mathrm{CO}_{2}$ emissions per item and the forecasted number of new "post express nonstop" service items (Table 17) allow the projection of $\mathrm{CO}_{2}$ emissions 
for new service in the period from 2020 to 2025. The results of the forecasted number of postal items obtained by using the basic Bass model were used, as the validity of the model's implementation has been proven in the literature, through papers in the field of postal [61] and communication traffic [62], but also in numerous other fields [63]. Certainly, based on the resulting emission value per item, it would be easy to forecast $\mathrm{CO}_{2}$ emissions for each of the four scenarios, based on the modification of the Bass model proposed in the paper. However, it is clear that each of the considered scenarios brings us to the reduction of $\mathrm{CO}_{2}$ emissions.

The experiment was carried out in one part of the city of Belgrade; however, due to similar requirements and the relief structure of the city, as well as the development of the transport network, the obtained results can be approximated for research purposes to the whole city territory. It is believed that if the new service does not start functioning, all of its requirements will be transferred to the existing daily services. Accordingly, Table 21 shows the results of comparative analysis of diesel consumption for requests (items) belonging to a new service in relation to the same requests, if they were realized through existing services. The $\mathrm{CO}_{2}$ emission for the same case is presented in Figure 6 .

Table 21. Results of comparative analysis of diesel consumption in the period from 2020 to 2025.

\begin{tabular}{cccc}
\hline Year & Diesel-Existing Service (Liters) & Postal Items & Diesel-New Service (Liters) \\
\hline 2020 & 2719.837855 & $57,069.798$ & 2002.22595 \\
2021 & 3569.676685 & $74,901.7913$ & 2627.840215 \\
2022 & 4622.345668 & $96,989.72793$ & 3402.769187 \\
2023 & 5920.131701 & $124,220.9052$ & 4358.142636 \\
2024 & 7510.990743 & $157,601.5731$ & 5529.263646 \\
2025 & 9447.610994 & $198,237.2773$ & 6954.918972 \\
\hline Total & $33,790.59365$ & $709,021.0728$ & $24,875.16061$ \\
\hline
\end{tabular}

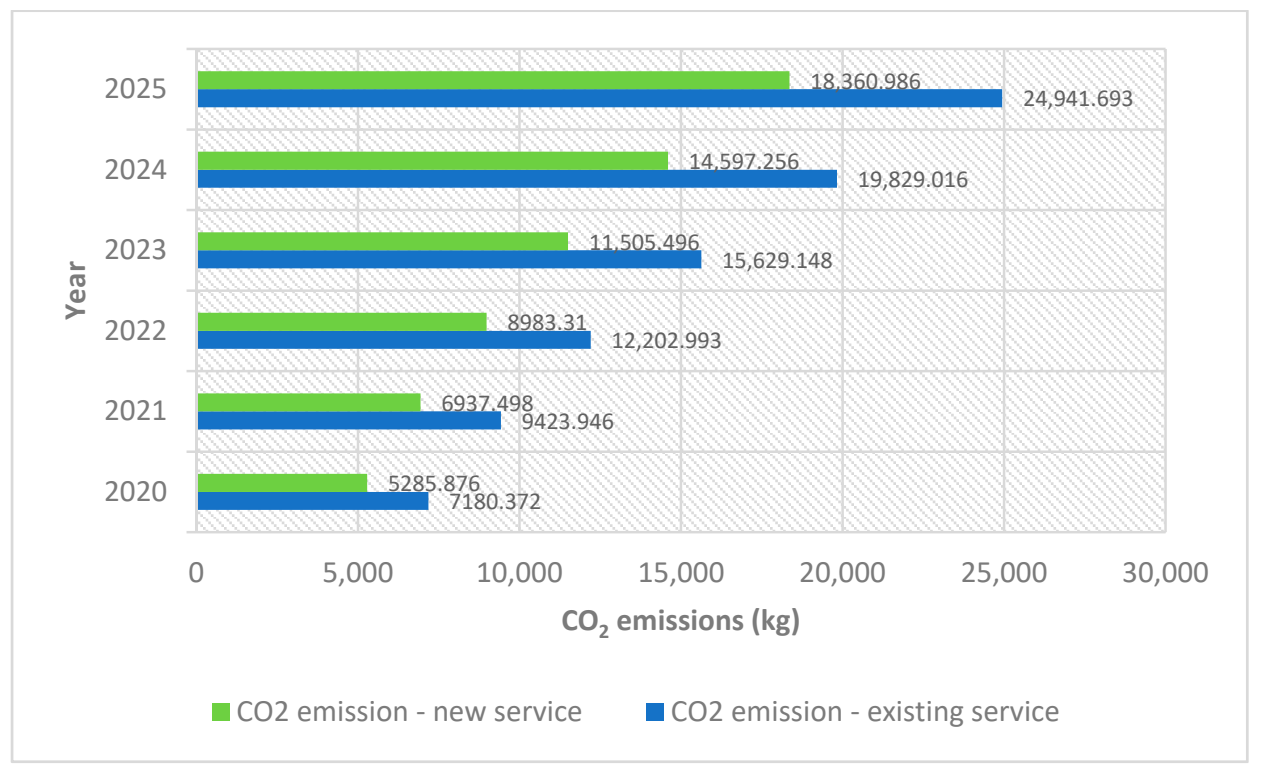

Figure 6. $\mathrm{CO}_{2}$ emissions for new service in the period from 2020 to 2025 .

Based on the obtained results, it is concluded that for the period 2020-2025, if a new service would be introduced, $\mathrm{CO}_{2}$ emissions would be $23.5 \mathrm{t}$ lower. It should be noted that the forecast was made only for the territory of the city of Belgrade, which means that the savings would be more pronounced if the forecast covered a larger territory. Moreover, if other postal operators, of which there are about 50 in the Republic of Serbia, offer similar service, the reduction of negative environmental impacts through $\mathrm{CO}_{2}$ emissions would be even more significant. The calculation does not include the possibility that the same number of items in night conditions could be delivered in a shorter period of time than is the 
case in daily conditions. In addition to the evident reduction of $\mathrm{CO}_{2}$ emissions, there are many other positive effects of introducing a new service, such as reducing fuel costs for the company and reducing other harmful emissions and congestion in the daily traffic conditions.

\section{Conclusions}

Better time availability is a prominent competitive market advantage of an organization. This paper analyzes the express delivery service of the designated postal operator in Serbia, on the territory of Belgrade. The analysis was performed in line with the proposed methodology, in several steps. Primarily, after the current state of time availability was analyzed, the conclusion was that there are certain periods of time when the observed service is not implemented.

In line with the above stated, an activity is proposed that involves the formation and offering of a new service, "post express nonstop", to be performed during the mentioned periods of time (overnight, as well as daytime periods over the weekend).

Relevant research was conducted in order to analyze the current situation (users' views and opinions on express service delivery) and validity (requirements, needs, and interests of potential and existing users for the introduction of the "post express nonstop" service). The results of the research are presented in detail. Based on the results, it was noticed that the most commonly used delivery service was Today for Tomorrow. Regarding the proposed new service, the results showed that most legal entities and approximately every second natural person had a need for the service in the previous year. Moreover, there is a considerable amount of interest for the proposed service, especially among respondents who are users of some of the existing express delivery services.

With an aim to realize the future of this service on the market, a forecast of the acceptance was made for a five-year period. By introducing the imitation corrected factor, which is one of the contributions of this paper, four service-acceptance scenarios were created. Since even in a pessimistic scenario there is a significant number of postal items for the analyzed service, a conclusion can be drawn that the market is ready for its introduction.

An analysis of the impact of the new "post express nonstop" service on $\mathrm{CO}_{2}$ emissions was conducted. This involved simulating the delivery of postal items on the territory of the city of Belgrade in different periods of the day and controlling diesel consumption. The obtained results led to the conclusion that the savings in diesel consumptions, on the side of new service, amount to about $26 \%$ compared to that of the existing service. Diesel consumption was used to calculate $\mathrm{CO}_{2}$ emissions, so it is clear to see a positive effect. In accordance with the forecasted number of items for the new "post express nonstop" service, the $\mathrm{CO}_{2}$ emission is projected for the period 2020-2025. In this way, the positive impact of the new service on the environment in the future was demonstrated.

In the technological process of postal-item transfers, there are other sources of negative environmental impacts (such as processing and sorting activities) that need to be identified, analyzed, and promoted in a positive environmental sense. In addition, special attention should be paid to driver training and the promotion of eco-driving, which can further contribute to reducing $\mathrm{CO}_{2}$ emissions. One of the further directions of research can be the formation of an ecological image of the traffic network of the whole city, at different periods of time (within $24 \mathrm{~h}$ ) and its use as a criterion, when creating appropriate routes.

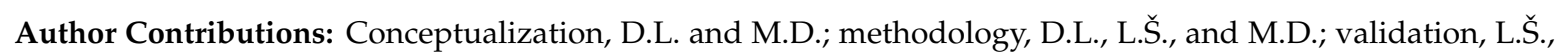
V.R. and M.D.; formal analysis, D.L.; investigation, D.L.; resources, L.Š. and V.R.; data curation, D.L. and M.D.; writing—original draft preparation, D.L., V.R., and M.D.; writing—review and editing, D.L., L.Š., V.R., and M.D.; visualization, D.L.; supervision, L.Š., V.R., and M.D. All authors have read and agreed to the published version of the manuscript.

Funding: This research received no funding from any project.

Conflicts of Interest: The authors declare no conflict of interest. 


\section{References}

1. Agronick, G.S.; Duncan, L.E. Personality and social change: Individual differences, life path, and importance attributed to the women's movement. J. Personal. Soc. Psychol. 1998, 74, 1545. [CrossRef]

2. Glenn, S.S. Individual behavior, culture, and social change. Behav. Anal. 2004, 27, 133-151. [CrossRef]

3. Jakubowicz, K. Rude awakening social and media change in Central and Eastern Europe. Javnost Public 2001, 8, 59-80. [CrossRef]

4. Fourt, L.A.; Woodlock, J.W. Early prediction of market success for new grocery products. J. Mark. 1960, 25, 31-38. [CrossRef]

5. Mansfield, E. Technical change and the rate of imitation. Econom. J. Econom. Soc. 1961, 29, 741-766. [CrossRef]

6. Rogers, E.M. Diffusion of Innovations; The Free Press of Glencoe: Glencoe, IL, USA, 1962.

7. Floyd, A. Trend forecasting: A methodology for figure of merit. In Technological Forecasting for Industry and Government: Methods and Applications; Bright, J., Ed.; Prentice Hall: Englewood Cliffs, NJ, USA, 1962; pp. 95-105.

8. Chow, G.C. Technological change and the demand for consumers. Am. Econ. Rev. 1967, 57, 1117-1130.

9. Bass, F.M. A new product growth for model consumer durables. Manag. Sci. 1969, 15, 215-227. [CrossRef]

10. Radojicic, V. Forecasting in Telecommunication; Faculty of Transport and Traffic Engineering: Belgrade, Serbia, 2003.

11. Radas, S. Diffusion models in marketing: How to incorporate the effect of external influence? Privredna Kretanja i Ekonomska Politika 2005, 15, 30-51.

12. Santos, G. Road transport and $\mathrm{CO}_{2}$ emissions: What are the challenges? Transp. Policy 2017, 59, 71-74. [CrossRef]

13. Peng, T.; Zhou, S.; Yuan, Z.; Ou, X. Life cycle greenhouse gas analysis of multiple vehicle fuel pathways in China. Sustainability 2017, 9, 2183. [CrossRef]

14. European Parliament. $\mathrm{CO}_{2}$ Emissions from Cars: Facts and Figures (Infographics). 2019. Available online: https://www.europarl.europa.eu/news/en/headlines/society/20190313STO31218/co2-emissions-fromcars-facts-and-figures-infographics (accessed on 25 November 2019).

15. Takeshita, T. Global scenarios of air pollutant emissions from road transport through to 2050. Int. J. Environ. Res. Public Health 2011, 8, 3032-3062. [CrossRef] [PubMed]

16. Lu, L.; Han, X.; Li, J.; Hua, J.; Ouyang, M. A review on the key issues for lithium-ion battery management in electric vehicles. J. Power Sources 2013, 226, 272-288. [CrossRef]

17. Lopes, J.A.P.; Soares, F.J.; Almeida, P.M.R. Integration of electric vehicles in the electric power system. Proc. IEEE 2010, 99, 168-183. [CrossRef]

18. Tzeng, G.H.; Lin, C.W.; Opricovic, S. Multi-criteria analysis of alternative-fuel buses for public transportation. Energy Policy 2005, 33, 1373-1383. [CrossRef]

19. Carraretto, C.; Macor, A.; Mirandola, A.; Stoppato, A.; Tonon, S. Biodiesel as alternative fuel: Experimental analysis and energetic evaluations. Energy 2004, 29, 2195-2211. [CrossRef]

20. Murugesan, A.; Umarani, C.; Subramanian, R.; Nedunchezhian, N. Bio-diesel as an alternative fuel for diesel engines-A review. Renew. Sustain. Energy Rev. 2009, 13, 653-662. [CrossRef]

21. Bozbas, K. Biodiesel as an alternative motor fuel: Production and policies in the European Union. Renew. Sustain. Energy Rev. 2008, 12, 542-552. [CrossRef]

22. Saboohi, Y.; Farzaneh, H. Model for developing an eco-driving strategy of a passenger vehicle based on the least fuel consumption. Appl. Energy 2009, 86, 1925-1932. [CrossRef]

23. Sivak, M.; Schoettle, B. Eco-driving: Strategic, tactical, and operational decisions of the driver that influence vehicle fuel economy. Transp. Policy 2012, 22, 96-99. [CrossRef]

24. Ayyildiz, K.; Cavallaro, F.; Nocera, S.; Willenbrock, R. Reducing fuel consumption and carbon emissions through eco-drive training. Transp. Res. Part F Traffic Psychol. Behav. 2017, 46, 96-110. [CrossRef]

25. Fontaras, G.; Zacharof, N.G.; Ciuffo, B. Fuel consumption and $\mathrm{CO}_{2}$ emissions from passenger cars in Europe-Laboratory versus real-world emissions. Prog. Energy Combust. Sci. 2017, 60, 97-131. [CrossRef]

26. James, P.; Ito, K.; Buonocore, J.; Levy, J.; Arcaya, M. A health impact assessment of proposed public transportation service cuts and fare increases in Boston, Massachusetts (USA). Int. J. Environ. Res. Public Health 2014, 11, 8010-8024. [CrossRef] 
27. Jacobson, M.Z.; Colella, W.G.; Golden, D.M. Cleaning the air and improving health with hydrogen fuel-cell vehicles. Science 2005, 308, 1901-1905. [CrossRef]

28. Liddell, C.; Morris, C. Fuel poverty and human health: A review of recent evidence. Energy Policy 2010, 38, 2987-2997. [CrossRef]

29. Pollitt, K.J.G.; Chhan, D.; Rais, K.; Pan, K.; Wallace, J.S. Biodiesel fuels: A greener diesel? A review from a health perspective. Sci. Total Environ. 2019, 688, 1036-1055. [CrossRef] [PubMed]

30. Olawepo, J.O.; Chen, L.W.A. Health benefits from upgrading public buses for cleaner air: A case study of Clark County, Nevada and the United States. Int. J. Environ. Res. Public Health 2019, 16, 720. [CrossRef]

31. Radojičić, V.; Bakmaz, B.; Veličković, S. Prognoziranje Novih Telekomunikacionih Servisa; Faculty of Transport and Traffic Engineering: Belgrade, Serbia, 2013.

32. Kohli, R.; Lehmann, D.R.; Pae, J. Extent and impact of incubation time in new product diffusion. J. Prod. Innov. Manag. Int. Publ. Prod. Dev. Manag. Assoc. 1999, 16, 134-144. [CrossRef]

33. Van den Bulte, C.; Stremersch, S. Social contagion and income heterogeneity in new product diffusion: A meta-analytic test. Mark. Sci. 2004, 23, 530-544. [CrossRef]

34. Bone, P.F. Word-of-mouth effects on short-term and long-term product judgments. J. Bus. Res. 1995, 32, 213-223. [CrossRef]

35. Anderson, E.W. Customer satisfaction and word of mouth. J. Serv. Res. 1998, 1, 5-17. [CrossRef]

36. Allsop, D.T.; Bassett, B.R.; Hoskins, J.A. Word-of-mouth research: Principles and applications. J. Advert. Res. 2007, 47, 398-411. [CrossRef]

37. Bayus, B.L. Word of mouth-the indirect effects of marketing efforts. J. Advert. Res. 1985, 25, 31-39.

38. Chang, J.H.; Wang, S.H. Different levels of destination expectation: The effects of online advertising and electronic word-of-mouth. Telemat. Inform. 2019, 36, 27-38. [CrossRef]

39. Stanton, S.J.; Kim, J.; Thor, J.C.; Deng, X. Incentivized methods to generate electronic word-of-mouth: Implications for the resort industry. Int. J. Hosp. Manag. 2019, 78, 142-149. [CrossRef]

40. Stojmenovic, M.; Biddle, R.; Grundy, J.; Farrell, V. The influence of textual and verbal word-of-mouth on website usability and visual appeal. J. Supercomput. 2019, 75, 1783-1830. [CrossRef]

41. Fisher, J.C.; Pry, R.H. A simple substitution model of technological change. Technol. Forecast. Soc. Chang. 1971, 3, 75-88. [CrossRef]

42. Putsis, W.P., Jr. Temporal aggregation in diffusion models of first-time purchase: Does choice of frequency matter? Technol. Forecast. Soc. Chang. 1996, 51, 265-279. [CrossRef]

43. Lenk, P.J.; Rao, A.G. New models from old: Forecasting product adoption by hierarchical Bayes procedures. Mark. Sci. 1990, 9, 42-53. [CrossRef]

44. Sultan, F.; Farley, J.U.; Lehmann, D.R. A meta-analysis of applications of diffusion models. J. Mark. Res. 1990, 27, 70-77. [CrossRef]

45. Robinson, B.; Lakhani, C. Dynamic price models for new-product planning. Manag. Sci. 1975, 21, 1113-1122. [CrossRef]

46. Gatignon, H.; Eliashberg, J.; Robertson, T.S. Modeling multinational diffusion patterns: An efficient methodology. Mark. Sci. 1989, 8, 231-247. [CrossRef]

47. Norton, J.A.; Bass, F.M. A diffusion theory model of adoption and substitution for successive generations of high-technology products. Manag. Sci. 1987, 33, 1069-1086. [CrossRef]

48. Horsky, D.; Simon, L.S. Advertising and the diffusion of new products. Mark. Sci. 1983, 2, 1-18. [CrossRef]

49. Jain, D.C.; Rao, R.C. Effect of price on the demand for durables: Modeling, estimation, and findings. J. Bus. Econ. Stat. 1990, 8, 163-170.

50. Bass, F.M.; Krishnan, T.V.; Jain, D.C. Why the Bass model fits without decision variables. Mark. Sci. 1994, 13, 203-223. [CrossRef]

51. Manceau, D.; Eliashberg, J.; Rao, V.R. A New Diffusion Model for Preannounced Products; Snider Entrepreneurial Center, The Wharton School, University of Pennsylvania: Philadelphia, PA, USA, 2001.

52. Mahajan, V.; Sharma, S.; Buzzell, R.D. Assessing the impact of competitive entry on market expansion and incumbent sales. J. Mark. 1993, 57, 39-52. [CrossRef]

53. Ganesh, J.; Kumar, V. Capturing the cross-national learning effect: An analysis of an industrial technology diffusion. J. Acad. Mark. Sci. 1996, 24, 328-337. [CrossRef]

54. Abedi, V.S.; Berman, O.; Krass, D. Supporting new product or service introductions: Location, marketing, and word of mouth. Oper. Res. 2014, 62, 994-1013. [CrossRef] 
55. Dias, P.A.P.; Yoshizaki, H.; Favero, P.; Vieira, J.G.V. Daytime or overnight deliveries? Perceptions of drivers and retailers in São Paulo City. Sustainability 2019, 11, 6316. [CrossRef]

56. Pallant, J. SPSS Survival Manual: A Step by Step Guide to Data Analysis Using SPSS; Allen \& Unwin: Crows Nest, Australia, 2011.

57. Mahajan, V.; Muller, E.; Wind, Y. (Eds.) New-Product Diffusion Models; Springer Science \& Business Media: Berlin, Germany, 2000.

58. Satoh, D. A discrete bass model and its parameter estimation. J. Oper. Res. Soc. Jpn. 2001, 44, 1-18. [CrossRef]

59. Khan, M.I.; Islam, M.R. True Sustainability in Technological Development and Natural Resource Management; Nova Science Publishers: Hauppauge, NY, USA, 2007.

60. Batalla, I.; Knudsen, M.T.; Mogensen, L.; del Hierro, Ó.; Pinto, M.; Hermansen, J.E. Carbon footprint of milk from sheep farming systems in northern Spain including soil carbon sequestration in grasslands. J. Clean. Prod. 2015, 104, 121-129. [CrossRef]

61. Dobrodolac, M.; Ralević, P.; Švadlenka, L.; Radojičić, V. Impact of a new concept of universal service obligations on revenue increase in the post of Serbia. PROMET Traffic Transp. 2016, 28, 235-244. [CrossRef]

62. Fildes, R.; Kumar, V. Telecommunications demand forecasting-A review. Int. J. Forecast. 2002, 18, 489-522. [CrossRef]

63. Meade, N.; Islam, T. Modelling and forecasting the diffusion of innovation-A 25-year review. Int. J. Forecast. 2006, 22, 519-545. [CrossRef]

(C) 2020 by the authors. Licensee MDPI, Basel, Switzerland. This article is an open access article distributed under the terms and conditions of the Creative Commons Attribution (CC BY) license (http://creativecommons.org/licenses/by/4.0/). 